\title{
Article
}

\section{Oleg Zatsarinny (1953-2021): Memories by His Colleagues}

\author{
Klaus Bartschat ${ }^{1, *(\mathbb{D})}$, Charlotte Froese Fischer ${ }^{2}(\mathbb{D})$ and Alexei N. Grum-Grzhimailo ${ }^{3}$ (D) \\ 1 Department of Physics and Astronomy, Drake University, Des Moines, IA 50311, USA \\ 2 Department of Computer Science, University of British Columbia, 2366 Main Mall, \\ Vancouver, BC V6T1Z4, Canada; cff@cs.ubc.ca \\ 3 Skobeltsyn Institute of Nuclear Physics, Lomonosov Moscow State University, 119991 Moscow, Russia; \\ algrgr1492@yahoo.com \\ * Correspondence: klaus.bartschat@drake.edu
}

check for

updates

Citation: Bartschat, K.; Fischer, C.F.; Grum-Grzhimailo, A.N. Oleg Zatsarinny (1953-2021): Memories by His Colleagues. Atoms 2021, 9, 109 https://doi.org/10.3390/atoms9040109

Academic Editor: Emmanouil P. Benis

Received: 11 November 2021

Accepted: 30 November 2021

Published: 7 December 2021

Publisher's Note: MDPI stays neutral with regard to jurisdictional claims in published maps and institutional affiliations.

Copyright: (c) 2021 by the authors. Licensee MDPI, Basel, Switzerland. This article is an open access article distributed under the terms and conditions of the Creative Commons Attribution (CC BY) license (https:// creativecommons.org/licenses/by/ $4.0 /)$.
Abstract: A collection of short stories about Oleg Ivanovich Zatsarinny (1953-2021) to whom this Special Issue of Atoms is dedicated.

Keywords: B-spline R-matrix; atomic structure; electron collisions; photoionization; atomic data for plasma and astrophysics

\section{Introduction}

In this contribution to the Special Issue of Atoms in honor of Oleg Zatsarinny, we collect a number of short essays written by his colleagues and friends. It is a mixture of science and personal stories, intended to present a picture of Oleg as a research scientist, a teacher, and simply a human being.

\section{Individual Memories}

We start this section with some memories of the three guest editors. Some attempt to order the remaining contributions was made, with groups formed after accounting for geography and topic, such as fundamental research and outreach into applications, particularly in plasma and astrophysics. The authors/teams of the individual contributions are listed in the headers of the various subsections.

\subsection{Alexei N. Grum-Grzhimailo (Lomonosov Moscow State University, Moscow, Russia)}

I first met Oleg in 1978 during a short business trip from Moscow State University to Uzhgorod State University. More than 40 years have passed since then. I would like to write some words about my friend. I will start with a short history. In the late 1970s, the theoretical group of Prof. V.I. Lengyel at Uzhgorod State University changed fields from elementary particle physics to the physics of atomic collisions. At that time, experimental research in Uzhgorod already had a long and rich history in the latter area and was at the forefront of this direction in the Soviet Union. Therefore, such a reorientation was justified. Prof. Lengyel visited Moscow State University at that time, adopting our experience of working with the so-called "diagonalization approximation" to describe autoionization resonances. This is how the connection between our groups started. Oleg was one of several young physicists who had started to work in the group of V.I. Lengyel, while I was one of those who represented the Moscow group of theoreticians.

Since then, I met Oleg a countless number of times in Moscow, Uzhgorod, and at many national and later international conferences. In 1994 and later we worked a few times simultaneously at the University of Freiburg, and in 2005 we worked in parallel at Drake University. Our last personal meeting was during the summer of 2019 at a conference in Metz, France. Oleg and I published only a few joint articles scattered over the years, but in our friendly communication, science was only one of the topics we discussed. There were many scientific plans, but some of our joint abstracts never turned into regular articles. 
Once Oleg showed me the "working corner" in his Uzhgorod apartment. Copies of reviews and collections of articles in homemade bindings stood on two book-shelves. In those years, journals were only available in hardcopies, and there were no websites. A PC was standing on a small desk. Oleg adapted Fortran programs written for "large" machines to the PC, simultaneously optimizing them. Therefore, he knew thoroughly how these programs work. Since then, I think, Oleg had for the rest of his life the desire to get by, whenever possible, with a desktop computer and have a "pocket version" of large programs. The calculations sometimes took many days. Oleg organized periodic recordings of intermediate results in long-running programs, so that he could restart with them later. This was of critical importance, since in those times power outages happened rather often in Uzhgorod.

Oleg's approach to scientific problems was fundamental, without rush and jumping over stages. He proceeded like a tank. His results were eminently reliable. Prof. W. Mehlhorn from Freiburg University noticed a paper [1] on very accurate calculations of autoionizing states in sodium and started collaborating with Oleg. I was an eyewitness of how it started, because I already worked in Freiburg at that time. Electron spectroscopy of sodium and later barium atoms, excited by laser optical pumping and further ionized by electron impact, was a topic under development by Alexander Dorn, then a PhD student in Freiburg (now Alexander works at the Max-Planck-Institute for Nuclear Physics in Heidelberg) and other young group members, with whom Oleg actively communicated. His collaboration with the group of W. Mehlhorn resulted in a few excellent publications. See, for example, [2-6].

On several occasions, working in Freiburg on different, but related problems, we sometimes occupied opposite tables in the same office. Oleg, seeing my torment with the spectroscopy of autoionizing states of potassium, took the initiative and gave me instructions on how to efficiently use the MCHF code of Charlotte Froese Fischer. Problem solved! I have kept these compact records from 25 years ago, and I still look into them and benefit from them from time to time. Oleg also gave me first advice on using the Belfast RMATRX code. I was getting pseudo-resonances, and I was a novice in R-matrix theory; these were my first calculations [7]. Oleg pointed the pseudo-resonances out to me, and with great relief I then threw out incomprehensible spikes on the curves of the cross sections.

Oleg was always friendly, delicate, modest, and never refused scientific assistance to me, even with potential competition on some topics. He was a heavy smoker all the years I remember him. He told me that without smoking he couldn't think properly. I don't know how much it hindered him in different places of his work. He liked to watch soccer and tennis, combining it with drinking good beer. We've had all sorts of stories. Once we shared a 3-bedroom apartment in Freiburg, and he was the only guest on my 40th birthday (see Figure 1). At another time we invited the couples Werner and Marilot Mehlhorn and Volker and Annemaria Schmidt for a return visit. Before that, we noticed that they prefer the local Fürstenberg beer. Oleg bought a box of Fürstenberg. However, at the first sips, Volker made a puzzled face. It turned out that it was the non-alcoholic version! Oleg was terribly embarrassed and said: "Unbelievable, I chose the most expensive version of Fürstenberg!" The existence of non-alcoholic beers had not been known to us before. 


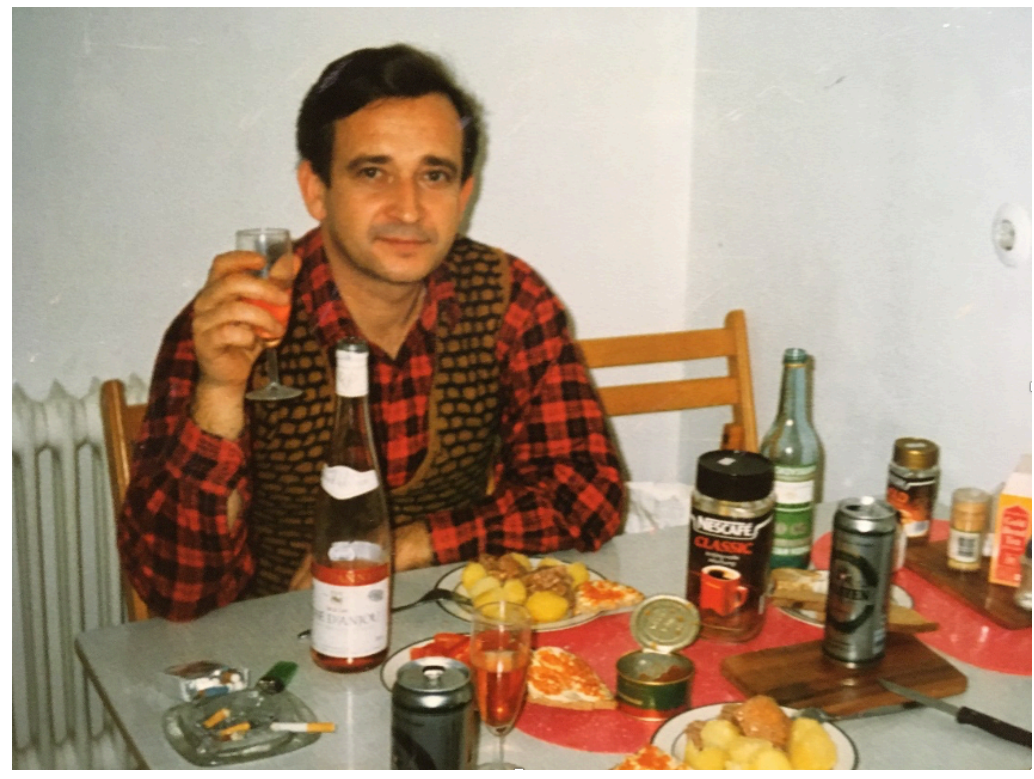

Figure 1. Oleg Zatsarinny. Freiburg, 30 November 1994. Photo from private collection of A.N. Grum-Grzhimailo.

When Oleg and I discussed physics, we understood each other perfectly. At the same time, it seems to me that we complemented each other well. Oleg was excellent and had incredible experience in counting spectra and cross sections. But sometimes he asked for help, especially when he needed advanced angular-momentum algebra, including matching the relative phases of the amplitudes. Of course, this also happened the other way around. Once I could not get the required sign of a matrix element for a long time. I complained to Oleg about the difficult life of theoreticians, who spend half of their lives looking for errors in phases. He listened and, without looking at the formulas, said that he knew where my sign had disappeared, and then outlined his version. Although this was said half as a joke, he hit the spot-I forgot to change the sign, "throwing" electrons over each other an odd number of times when reducing a multi-electron matrix element to a two-particle one. Oleg's "prediction" impressed me deeply.

I remember how happy Oleg was when he called informing me that Klaus Bartschat had invited him to Drake. [I worked with Klaus at Drake at that time.] Oleg was not yet well established in the USA in the early 2000s, and hence this was very important for him. I am sure that it was a good deal for both, Klaus and Oleg, and Drake became Oleg's affiliation for the rest of his life. Until his last days, Oleg, in spite of his busy schedule, helped my PhD student, who was learning to use Oleg's code, with BSR calculations. When I asked him to do this, Oleg said: "Yeah, you want to shove your PhD student onto me." This was said in a joking tone, but Oleg's help was decisive. Oleg almost made it before he passed away-now this student uses the BSR program on his own, but in difficult cases Oleg's experience is very lacking. This work resulted in a publication with the participation of Oleg [8] , explaining results of the very first beamtime at SQS (Small Quantum Systems) at the European X-ray free-electron laser (XFEL). The work on neon, which is included in this Special Issue with Oleg's co-authorship [9], could not have been completed without Oleg either.

The last time Oleg and his wife Tatyana came to Moscow was in August of 2016. They arrived a day or two before the start of a conference, and we sat, as before, in the kitchen of our apartment, talking and talking. Oleg and Tatyana were a very friendly and happily married couple.

Oleg's untimely departure is a huge loss for his loved ones. It is also a huge loss for atomic physics, along with its applications. He could have done so much more, and he could have taught many more people! 


\subsection{Klaus Bartschat (Drake University, Des Moines, Iowa, USA)}

I met Oleg for the first time at the same meeting at Rollins College in 2001 that Tom Gorczyca writes about in his contribution. Oleg gave a talk about his B-spline atomic R-matrix code, with some impressive early results that he had already obtained. After the session, there was a coffee break. During the break, Phil Burke, the father of the famous suite of Belfast R-matrix codes, came to me and said: "Klaus, you should try to bring this guy to Drake and work with you." I had worked with Phil as a PhD student and also for many years after getting the degree, and I knew right away that I should appreciate the advice of such a giant in atomic collision physics. Although this article is about Oleg, it is worth mentioning that Phil immediately saw the potential of the approach. Instead of playing the "territorial defense", Phil as a true gentleman gave us the strongest possible support for many years to come.

And we needed that support, as I found out in the fall of 2002. The NSF had just announced another round of the Information Technology Research (ITR) initiative, a program that was meant to fund high-risk-high-reward projects. At the time, Barry Schneider was the cognizant NSF program officer for the theoretical atomic, molecular, and optical physics (TAMOP) program of the NSF and also specifically in charge of dealing with all AMO proposals submitted to the ITR initiative. One of those proposals was mine. The one-and-only goal was to get Oleg to come to Drake and work full-time on his BSR code. The budget was correspondingly simple: Oleg's salary for three years, plus benefits and overhead-nothing else. [I had another NSF grant that could be used for typical operating expenses.] Barry, himself an expert on R-matrix methods, was quite skeptical about the method, but the proposal was sent out for review. I never received such a diverse range of ratings. Under normal circumstances, funding would likely have been declined. However, a very strong supporting letter from Phil Burke helped, and so did the summary remark in one of the reviews that essentially said this: "I (this reviewer) do not believe that this version of the R-matrix method can be competitive with the machinery already in place in Belfast. BUT: If it works, then this will be a gigantic step forward."

Due to the nature of the ITR initiative, Barry and the NSF rolled the dice and we got the money. Oleg came to Drake, and about half a year later, he showed me Figure 2 with the excitation function of the $\left(2 \mathrm{p}^{5} 3 \mathrm{~s}\right)^{3} \mathrm{P}_{2,0}$ metastable states that Steve Buckman had measured as a post-doc more than 20 years earlier [10]. No theory had been able to reproduce the data properly in the near-threshold resonance regime. The agreement was practically perfect, not just reproducing the resonance positions but also the relative height of the features as well as the effects of cascades. Oleg had to apply an overall normalization factor of 0.78 to the (absolute) published experimental numbers, but this factor was well within the experimental uncertainty.

From then on, things went uphill rapidly. After three years, the ITR program was finished, but the NSF started a program in Computational Physics. I wrote a "renewal proposal", and this time the reviewers' verdict was unanimous: 6 out of $6 \mathrm{E}$ (xcellent) ratings and another three years of full funding as requested-something quite unusual for NSF proposals. We published many, many papers on a variety of topics, and we also established excellent connections with many colleagues in the "applied physics community", most importantly those in plasma and astrophysics, while at the same time producing benchmark results of interest for fundamental AMO physics. 


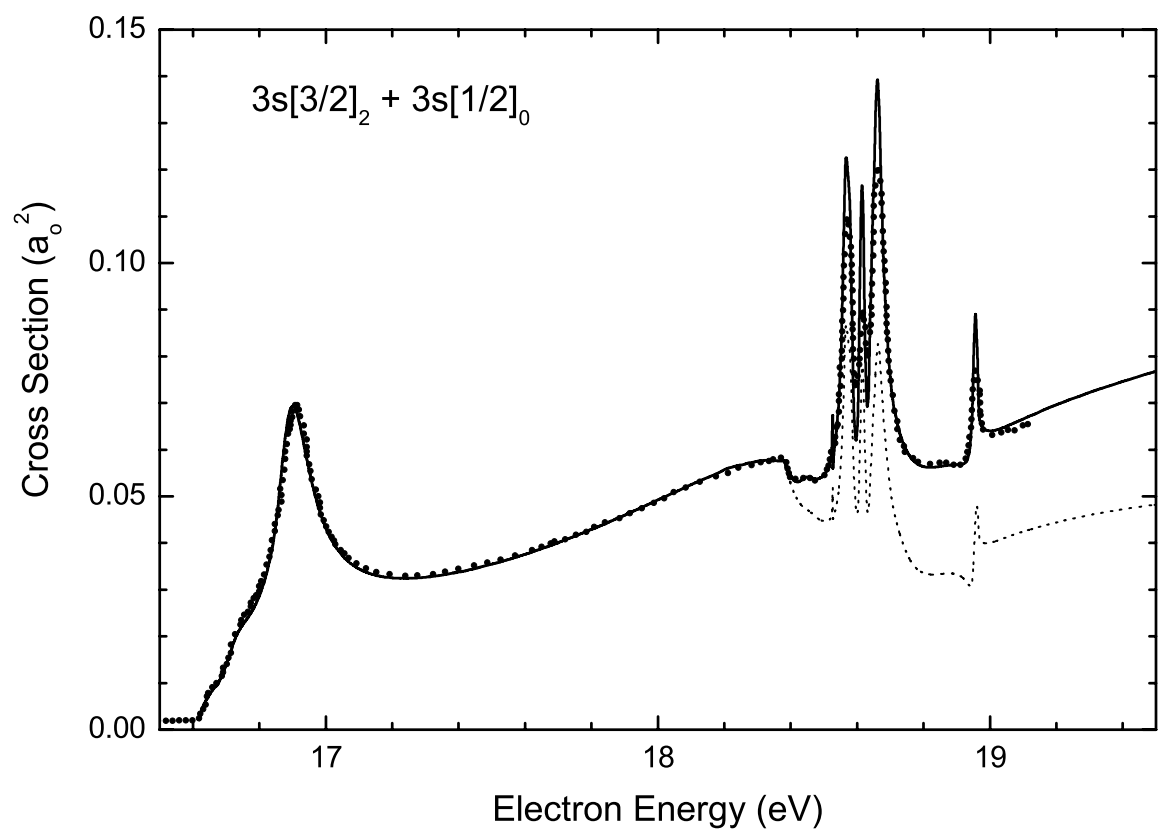

Figure 2. Angle-integrated cross section for production of neon atoms in the metastable states $3 s[3 / 2]_{2}$ and $3 s^{\prime}[1 / 2]_{0}$. The experimental data of Buckman et al. [10] (thick dots) were renormalized to provide a good visual fit to the theory at energies just above the excitation threshold. The solid line includes the cascade contributions from all the states included in the model, while the thin dotted line (starting around $18.4 \mathrm{eV}$ ) represents the results without cascades. Figure reproduced from Ref. [11].

After six years at Drake University with full funding of Oleg's salary, Oleg was classified as "too senior", and we were told that Drake needed to do something to keep Oleg employed. For two more three-year periods, a 50/50 deal was struck between Drake and the NSF-Oleg would teach one course per semester at Drake, and half of his 9-months salary would be paid by the university. That's when Oleg taught advanced classes (Mechanics, Electromagnetic Theory, Advanced Classical Mechanics, Quantum Mechanics) to junior and senior students, and he also developed a "Computational Physics" course that we did not have on the books until then. Taking Oleg's courses would not result in an "easy grade", but if the students put the effort in, they would learn a lot. Then, from 2016 until 2018, Oleg could only draw the normal two months of summer salary from his own grant in the Computational Physics program, which was also destined to be terminated at the NSF. In other words, things started to look problematic. An attempt to "piggy back" his project to my own TAMOP project failed. Fortunately, however, another avenue opened up in the Advanced Cyberinfrastructure program. With the help and advice of Bogdan Mihaila, we secured a grant in that project, which is still going on at this moment. Unfortunately, Oleg did not live to see the end of the project, but Kathryn Hamilton is making sure that the codes are maintained and even made more easily available on the AMOS (Atomic, Molecular, and Optical Sciences) gateway [12]. Thank you to the NSF program officers and the Drake administrators to make all this possible-apparently everybody realized that Oleg represented a tremendous asset.

Oleg was a cornerstone of my research group. Figure 3 shows a typical picture exhibiting our very international composition. The physicists not only got along very well with each other, but (before COVID-19 struck) we also had frequent dinners and other celebrations, either at one of the homes or in a park. Oleg and Tatyana always brought nice treats to the gathering. These often included a variety of treats from the European store but always a 6-pack of Pilsner Urquell-I don't know whether Oleg liked that particular beer, but he sure knew that I did. 


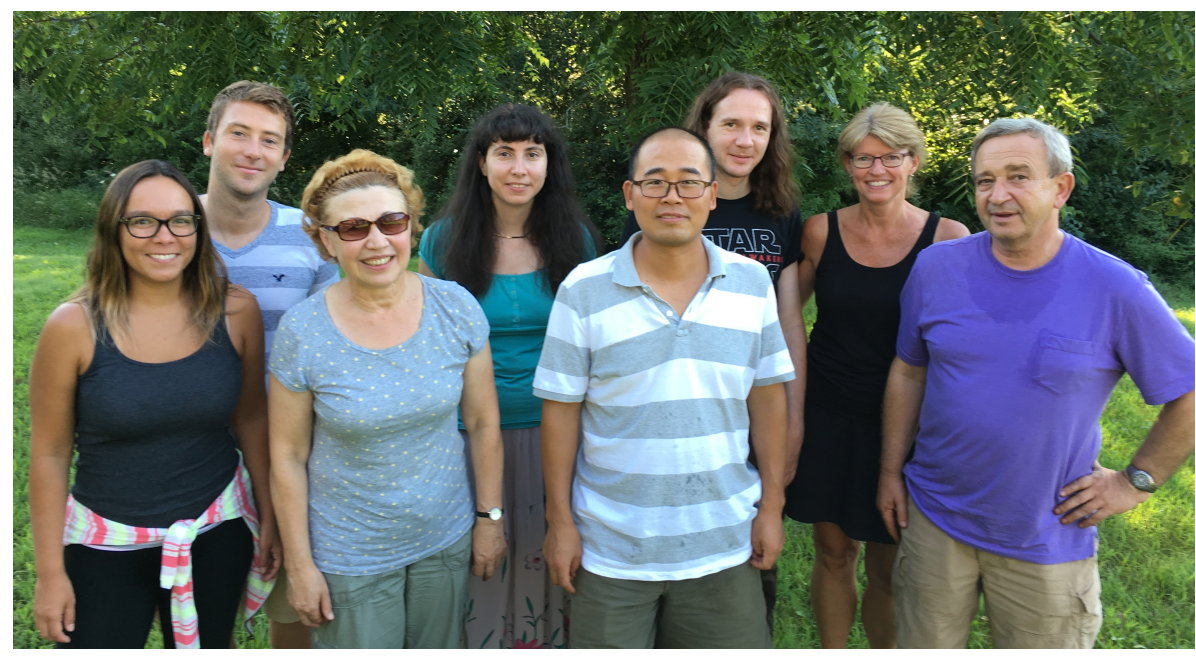

Figure 3. A group outing in 2017. From left to right with their countries of origin in parentheses: Samantha Fonseca (Brazil), Nicolas Douguet (France), Tatyana Zatsarinny (Ukraine), Raquel Pinto Álvarez (Spain), Kedong Wang (China), Luis Fernández-Menchero (Spain), Teresa Bartschat (Canada), and Oleg Zatsarinny (Ukraine). Photo from private collection of Klaus Bartschat.

\subsection{Charlotte Froese Fischer (University of British Columbia, Vancouver, Canada)}

Oleg was interested in all kinds of ideas about atoms. He was impressed with what I had done in my non-relativistic SPHF program using splines. Having just completed a relativistic R-matrix code, he had decided to prepare a Dirac version of SPHF that he called DBSR_HF. He invited me to Des Moines to assist him in debugging and the preparation of a manuscript for Computer Physics Communications. Instead of going to his office, he would pick me up every day from the motel and we would spend the day at his home. Most of the time was spent learning about how Oleg's program worked. It had many options. Although, it could be used at a very simple level—the command "dbsr_hf $\mathrm{Ne}^{\text {" }}$ will produce results for the ground state of neon-it can do some rather sophisticated calculations. In particular, it can produce fully relativistic total energies with Breit, vacuum polarization, and self-energy corrections, all broken down nicely for comparison with other theories. Oleg's wife, Tatyana, worked during the day, but always left us with a prepared lunch (see Figure 4). On her day off she cooked an impressive dinner with Ukrainian dishes, other nights we went out for dinner. They were wonderful hosts.

Oleg and I had many email conversations. When I wanted to test some new finitedifference code for solving variational equations from Dirac theory-faster and more accurate than before-I needed hydrogenic values of Slater integrals. In non-relativistic theory, these are rational numbers that can easily be obtained by symbol manipulation software, like Maple. But I was not aware of anyone having done this for Dirac theory, so I asked Oleg. He must have a vast storage of notes because he immediately responded with a table of Slater integrals (see Table 1) that he thought he might have derived using Mathematica. 


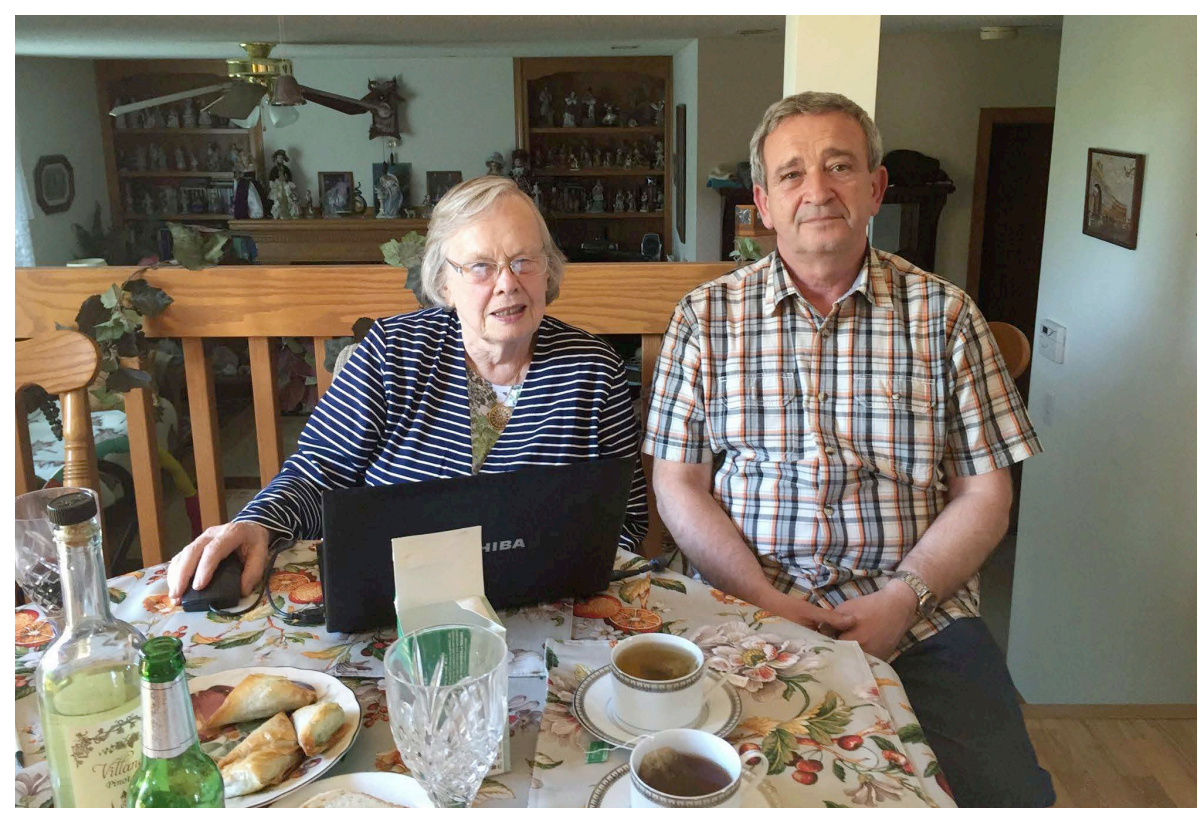

Figure 4. Charlotte and Oleg working on the DBSR_HF project (May 2015) at Oleg's home in West Des Moines. Photo from private collection of Charlotte Froese Fischer.

Table 1. Dirac-Slater integrals for hydrogen $(Z=1)$ to double-precision accuracy, as derived by Oleg for a point nucleus.

\begin{tabular}{cc}
\hline Integral & Value \\
\hline$R_{0}(1 \mathrm{~s}, 1 \mathrm{~s} ; 1 \mathrm{~s}, 1 \mathrm{~s})$ & 0.62501225565917420 \\
$R_{0}(1 \mathrm{~s}, 2 \mathrm{~s} ; 1 \mathrm{~s}, 2 \mathrm{~s})$ & 0.20988178946000520 \\
$R_{0}(1 \mathrm{~s}, 2 \mathrm{~s} ; 2 \mathrm{~s}, 1 \mathrm{~s})$ & 0.02194902302127903 \\
\hline$R_{0}(1 \mathrm{~s}, 2 \mathrm{p} ; 1 \mathrm{~s}, 2 \mathrm{p})$ & 0.24280005588417670 \\
$R_{0}(1 \mathrm{~s}, 2 \mathrm{p}-; 1 \mathrm{~s}, 2 \mathrm{p}-)$ & 0.24280528746571910 \\
$R_{1}(1 \mathrm{~s}, 2 \mathrm{p} ; 2 \mathrm{p}, 1 \mathrm{~s})$ & 0.05121117625724148 \\
\hline$R_{0}(1 \mathrm{~s}, 3 \mathrm{~d} ; 1 \mathrm{~s}, 3 \mathrm{~d})$ & 0.11102328042993430 \\
$R_{0}(1 \mathrm{~s}, 3 \mathrm{~d}-; 1 \mathrm{~s}, 3 \mathrm{~d}-)$ & 0.22128364373246080 \\
$R_{0}(2 \mathrm{p}, 3 \mathrm{~d} ; 2 \mathrm{p}, 3 \mathrm{~d})$ & 0.18528097106484610 \\
$R_{0}(3 \mathrm{~d}, 3 \mathrm{~d} ; 3 \mathrm{~d}, 3 \mathrm{~d})$ & 0.08604622596773348 \\
\hline
\end{tabular}

My last conversation with Oleg was about refereeing a submitted paper:

On Tuesday, 3 November, 06:17 PM CST, Charlotte wrote:

I agreed to referee a paper where collision strengths for specific transitions are reported. They refer to a Wang, Bartschat, Zatsarinny (2018) paper using BSR which I suspect included Breit-Pauli. Can I have a copy of your paper?

Did you vote today?! How are things going?

On Tuesday, 3 November 2020, 07:10 PM CST, Oleg responded:

That makes two of us -I was also assigned as referee to this paper. Attached is a copy of our paper.

The present paper is a step further-it considers fine-structure transitions. However, the accuracy of target states is still far from accurate, to such extent that to bother about small Breit corrections makes no sense, I think. And it is a problem of modern atomic-structure software - nobody yet gets accurate description of transition elements with open $3 d$ shells, especially for scattering calculations where configuration expansions should be rather restricted. 
No, I did not vote, it is far from my life, I am still Russian guy, and never feel myself as American. But it will be interesting to follow all this performance ...

Due to some health I don't work much these days.

He had his unique way of writing and remained Russian at heart. For some reason, Oleg was not interested in bound-state problems-it was the scattering physics that interested him. Yet, in transition elements with their open d-shells and lanthanides with open f-shells, accurate targets are essential. It is unrealistic to assume that, in $3 d^{6} 4 s^{2}$ of Fe I, the ground state has six equivalent orbitals, all with the same radial function. Dirac theory helps in that there are two orbitals available ( $3 \mathrm{~d}$ and $3 \mathrm{~d}-$ ) for describing the physics. And then there is the correlation within the $3 s^{2} 3 p^{6} 3 d^{6}$ subshell. Oleg's work is unfinished in this respect. It will be interesting to see how much progress will be made in the future.

\subsection{Athanasios Petridis (Drake University, Des Moines, Iowa, USA)}

Oleg (Aliêg) Zatsarinny (see Figure 5) and I met for the first time when he joined the Department of Physics and Astronomy at Drake University. Initially he was hired as a Senior Research Scholar but soon his involvement with the Department expanded to include teaching of various upper-level courses. At the beginning our encounters were sparse but, with time, they became more frequent and a friendship gradually developed. This connection was boosted by the fact that my wife, Svetlana, is a native Russian speaker. Hence she could communicate with Oleg and his wife, Tatyana, very easily, sharing the same culture. I would often join in to learn and enjoy.

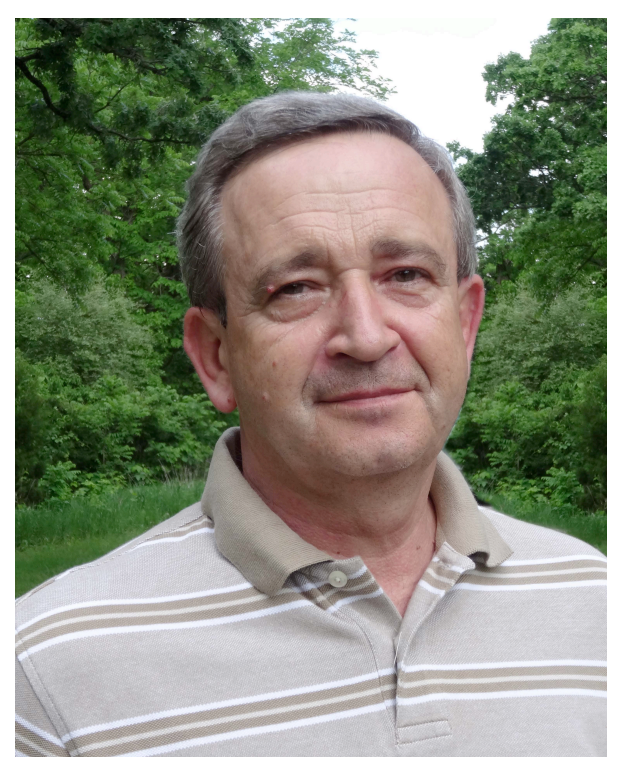

Figure 5. Oleg Zatsarinny. Photo from the official obituary.

Working with Oleg became more extended and our friendship grew much closer when I served as the Chair of the Department for six years. We communicated a lot about courses and pedagogy. Oleg could teach anything as his knowledge was vast, diverse and deep. However, he did not like to talk about his abilities or credentials. His courses emphasized content and rigor. Not all students were able to appreciate this but, in the end, everyone who took his classes benefited from his profound understanding of physics and his experience. In particular, his original course on Computational Physics educated many students on this very important and useful subject and prepared them for further academic research or professional careers. His approach had no fanfare. It was straightforward and to the point. It had all the scientific specificity that many non-experts may misinterpret as dryness but which is highly appreciated by professional scientists and students alike. 
Talking with him about teaching helped me realize that he harbored a sincere empathy towards his students. He cared. He was profoundly kind.

For Oleg everything was centered on work and everything had to be functional serving the ultimate purpose of doing research, teaching and understanding how Nature functions. When our department building underwent major renovations and we had to move everything out and, then, back into the renovated spaces, Oleg was there to help. Nobody will forget his figure standing or pacing in front of the building every day thinking about-what else?-physics research. My wife and I like to take long walks in the parks in West Des Moines where we would often meet Oleg and Tatyana who were taking even longer walks. One may wonder what this addiction of many physicists to walking is. It is not just for health. A quick study of the history of physics and the biography of some of its most prominent workers will reveal that the best minds among them used walking to clear their thoughts, to discuss multiple topics with other people and to ferment new ideas. The brain of the physicist keeps working on the problems even when the physicist does not consciously work. This characterized Oleg throughout all the years I knew him. I enjoyed our walking conversations and I felt I was walking side by side with one of those beautiful minds.

Oleg was friendly and helpful to those around him at a personal level. However, his own life was not trivial or easy. He, just like many others, belong to a generation of scientists who received very high-level education in the former Soviet Union and developed very strong careers there. When the Soviet Union collapsed the emerging countries, including Ukraine and Russia, faced enormous economic crises. The laboratories and the factories were closing. The great universities did not have enough funding to perform their educational and scholarly duties. Millions of people were literally at the brink of starvation and many did not survive. Amidst this extraordinarily difficult situation a large number of those scientists sought employment and possibly a new life in Western countries, most notably in Europe and North America. The academic and industrial sectors in these countries were eager and enthusiastic to provide them with jobs in order to use their expertise, their knowledge, some of which was new to the West, and their experience. However, the new lands were not equally eager to ensure that these people had stable employment to continue their work uninterrupted and without fear. Very few were lucky to finally find permanent positions. A large number of formerly Soviet scientists had to move from one institute to another or even from one country to another. It is a spectacular achievement that Oleg, among others, managed not only to continue his efforts but to produce some of his best work in his adopted new country, the United States. Drake University, particularly Klaus Bartschat, was able to secure external funding to provide a position for him. His contributions, in turn, made the continuation and expansion of external funding possible. Adversity fueled the strongest perseverance and ingenuity, the most passionate desire to create and reach new goals. Sincere gratitude and respect are in order. Oleg was a major contributor to computational atomic physics. He published about 400 articles alone and with collaborators and accumulated thousands of citations.

Oleg was a scientist and a family man. His love and dedication to his wife and son were obvious under all circumstances. He did not talk much but his words were meaningful. A few days before his passing he wrote to me about his concerns. Those were the thoughts of a caring individual. I will not attempt to end with a conclusion - not only because this is not a scientific paper but because, in my view, Oleg's life continues in the minds and hearts of all of us who have been touched by it. He was a good man.

\subsection{Adina Kilpatrick (Drake University, Des Moines, Iowa, USA)}

I met Oleg when I started at Drake in 2011. Oleg was not a very talkative person, so we didn't interact much outside the department meetings or socials. Even after I started as Chair in the fall of 2019, this unfortunately continued, as the pandemic restrictions and Oleg's illness limited our interactions. But even without much interaction, I knew from the beginning that Oleg was an outstanding physicist and felt that he was a genuine and 
kind person. To some extent, we shared a common background and similar challenges as immigrants from Eastern Europe/former Soviet Union.

Oleg's knowledge and expertise were incredibly vast and rigorous. He used it in teaching many of the difficult upper-level courses in our department over the years. Notably, he developed a Computational Physics course, a much-needed addition to our curriculum. He was an outstanding and prolific researcher whose contributions to the field of atomic physics cannot be overstated. Beyond his significant contributions to our department in terms of teaching and scholarship, he was a wonderful colleague and a supportive and caring mentor for our students. Although exceptionally accomplished, he was unassuming and modest about his accomplishments. I admired his knowledge, quiet strength, and perseverance in the face of adversity.

Oleg will be deeply missed as a colleague, instructor, researcher, and, above all, as a friend.

\subsection{Kathryn R. Hamilton (Drake University, Des Moines, Iowa, USA)}

I first met Oleg in March 2019 when I moved to Des Moines to take up a post-doctoral research position at Drake University. Oleg and his B-spline R-matrix code had a formidable reputation - it seemed that several of my fellow PhD students at The Queen's University of Belfast lived in a state of constant fear that Oleg would publish research on a particular topic before they could, as his calculations and analysis were often considered the "final word" on most atomic collision matters. After meeting Oleg in person, it became apparent that not only was he a uniquely talented researcher, but also an incredibly humble, kind, and generous individual.

Oleg was deeply passionate about his research, believing that if something was worth doing, it was worth doing well. This quest for perfection is also reflected in how he organized his data. Just like his computer, his office bookcase contains one folder for every element he worked on, filled with relevant papers and even extracts of emails. He was an excellent mentor too, who provided me with a wealth of books, papers, and annotated pieces of code, and also the occasional chastisement for not asking enough questions. Before his passing, Oleg worked tirelessly to package together the latest version of his BSR code, along with updated documentation and test cases, which he made publicly available through GitHub [13]. He was also one of the original members of the AMOS Gateway project [12], which seeks to make cutting-edge atomic physics codes such as BSR more accessible to the wider AMO community. We hope that continuing this work, thus ensuring that Oleg's BSR code will be used for many years to come, will be a fitting tribute to his scientific legacy.

However, Oleg was much more than just a brilliant researcher, he was also an incredibly kind, generous, and humble person. He frequently offered to drive me home from work, despite, as I much later found out, the considerable detour from his usual commute. Oleg would also keep me company at staff socials, joining me for second, and possibly third, rounds of ice-cream or popcorn. I really wish that there had been more time to learn from him, and to enjoy his company. He was an integral member of the Drake Physics and Astronomy department, and there are so many different ways in which we will miss him. The afternoons seem much quieter now without the sounds of Champion's League matches drifting through from the office next door.

2.7. Former Students David Atri-Schuller, Doug Drake, Molly McCord, Thomas Pauly, and Will Thomas (Drake University, Des Moines, Iowa, USA)

Dr. Zatsarinny was not only a dedicated researcher and scientist, but he was also an attentive and ardent professor. He taught a variety of classes, but where his passion truly showed was through his Computational Physics course. Not only was Dr. Zatsarinny actively engaged during lecture, but he was always available and willing to help students after class and during office hours (given the occasional smoke break, of course). These words can only go so far as to illuminate who Dr. Zatsarinny was as a professor. The best way to understand who he was is through the words of some of his former students. 


\subsubsection{David Atri-Schuller, Graduate Student at Stanford University, Palo Alto, California, USA}

I had the privilege of taking a computational physics course from Dr. Zatsarinny during my undergraduate studies at Drake. The course introduced me to the exciting research field of Computational Atomic Physics, while allowing me to appreciate Dr. Zatsarinny's physics mastery. He always had an abundance of teaching materials and methods to illustrate advanced techniques and was happy to spend as much time as the students needed to understand the concept. I recall visiting his office a particular time to discuss some details regarding the numerical calculations of large factorials, where he patiently walked me through various programs until I had understood the core ideas. Dr. Zatsarinny was kind and humble, and deeply cared about his students and colleagues. I feel truly honored to have been one of his students and look forward to seeing the continued impact of his work within the physics community.

\subsubsection{Doug Drake, Graduate Student at The University of Missouri-Kansas City, Kansas City, Missouri, USA}

In addition to taking Theoretical Mechanics, I took Computational Physics with Dr. Zatsarinny. When I started my undergrad, programming and modeling was at the bottom of my interests. Ironically enough, when I started my graduate studies, I joined a research group where my role is mainly computational modeling. I attribute part of that to my experience in Dr. Zatsarinny's class. To be completely honest, I hated it at first, I found FORTRAN frustrating and dense, and I spent hours in his office asking simple questions all things considered and venting about how difficult I found this class. It was around halfway through the semester that it started to click, and I started to understand what the class was trying to convey. It was highly independent and effectively taught me how to properly pace myself on complex problems and how to be patient when the programs didn't go the way that I wanted them to. By the end of the semester, I had a much better understanding and grew to love playing around with models on my computer, both in my Physics and Mathematics studies. One project that stood out was modeling the linear momentum of atoms and comparing them based on their valence shells. This easily took up hours of my time, and a lot of emails to Dr. Zatsarinny, but I didn't have the same sense of frustration that I had towards the beginning of the semester.

I didn't have many experiences with Dr. Zatsarinny after these classes, but I always passed by him when he would smoke by the bus stop. We would usually talk for a couple of minutes, nothing much more than small talk most of the time, but he always asked how I was doing and was genuinely interested in making sure that I had found my proper footing. If I had really anything else to say about Dr. Zatsarinny, it is that he cared deeply about the students in his classes and was always welcoming, I never felt intimidated asking him for help in or out of class. I had a lot of respect for Dr. Zatsarinny, and hearing of his passing was heartbreaking. The world lost a powerhouse of knowledge, and he will be missed.

\subsubsection{Molly McCord, Graduate Student at The University of Wisconsin-Madison, Madison, Wisconsin, USA}

I had the pleasure of knowing Dr. Zatsarinny through his Computational Physics class. He was an intense lecturer, and always spoke with a passion. Outside of class, he was relatively quiet, but always happy to help. When I entered that class, I had no background on anything computational, and I left that class with a confidence in my abilities using FORTRAN (despite the horrified looks that I get when people find out that I use FORTRAN). When it came to research, it was obvious that he was eager in the pursuit of knowledge, yet he was one of the humblest people I have ever met. While I did not know Dr. Zatsarinny for long, he taught me innumerable lessons on what it means to be a scientist that I will carry with me through my life. 


\subsubsection{Thomas Pauly, Software Engineer at Forsman Farms, Howard Lake, Minnesota, USA}

During Dr. Zatsarinny's time as a senior researcher and educator at Drake University, I knew him as my professor and as a revered physicist. He was a straightforward and helpful professor in the several classes I took with him. In his Computational Physics course, he introduced us to many numerical fundamentals, as well as how to apply them to classical and quantum mechanics. This course introduced me to many new resources and methods to use as a researcher and programmer. I am extremely thankful that I met Dr. Zatsarinny and was able to learn from someone so important in the field I was studying.

\subsubsection{Will Thomas, Graduate Student at The University of Wisconsin-Madison, Madison, Wisconsin, USA}

Dr. Zatsarinny was a good man, and I had the pleasure of taking both Theoretical Mechanics and Computational Physics classes from him. Although his passion was in research and not teaching, Dr. Zatsarinny made sure to explain everything thoroughly to his students. If he found out we did not understand a topic, he would be sure to spend the rest of class clarifying it. In one case we spent an hour talking about Fourier transforms as it was the class' first time encountering them and "criminal" that our math department had not taught it yet. Dr. Zatsarinny was also always available to talk about any issues in his Computational Physics class, ranging from compilers to his expertise on B-splines. Although I only had him for two classes, it was crystal clear to me by the voracity in which he hit his ruler against the Harvey Ingham TVs while lecturing that he was extremely passionate about physics.

\subsection{Luis Fernandez-Menchero (Queen's University of Belfast, Northern Ireland)}

I first met Oleg, together with Klaus, at the ICPEAC 2015 conference in Toledo (Spain). Oleg and Klaus had very interesting posters about the B-Spline R-Matrix (BSR) method applied to atomic collisions, and I was impressed by the accuracy of their atomic data. I established a conversation with both of them about the physics displayed on their posters. At that time, I was finishing my post-doctoral appointment at Strathclyde University, and I was looking for a new position. Fortunately, they were also looking for a post-doc to join their team. So, I decided to apply for that position, and I had the honor of working for two years with Oleg and Klaus at Drake University in Des Moines, Iowa. These were really two productive and happy years. As an example, I only mention here our work to calculate the electron-impact excitation of $\mathrm{N}^{3+}$ with the BSR method [14].

During these two years, I learned a lot from Oleg about the BSR method. It is arguably the most accurate approach within the R-matrix methodology, but also the most expensive computationally. I cannot say anything more about the professional life of Oleg than what the reader does not know already: several hundred published papers, thousands of citations, and all his different contributions clearly testify that he was a great scientist.

Oleg was also a great friend. He helped me with anything I needed, picking me up at the airport, looking for accommodation for me in Des Moines, offering his car for the move, driving me to any place I needed, lending me money until I received my first payment, and many other things that made my stay easier. We had several informal meetings, and they were great off-work time, partying, joking, and laughing with all the colleagues in the department together. In addition to being a well-known scientist, Oleg was a great person, best friend, a super-funny man and, I must add, a very good chess player.

Thank you for everything, Oleg.

2.9. Nicolas Douguet (Kennesaw State University, Atlanta, Georgia, USA) and Samantha Fonseca (Rollins College, Orlando Florida, USA)

Samantha and I moved to Des Moines in July 2015 to work at Drake University. We spent two beautiful years in Iowa and met fantastic people, among whom Oleg will always keep a special place in our hearts. I met Oleg for the first time in Klaus' backyard on a hot and humid summer day. Due to my background in electron-molecule scattering, 
I was aware of the success of Oleg's atomic BSR code. However, I did not know about the technical details. As I was trying to ask questions about the BSR code that day, I quickly realized that it was not the way Oleg had planned to spend his time on this beautiful summer afternoon! He was certainly right, and I have always admired the fact that Oleg was a brilliant physicist, performing cutting-edge calculations in atom-electron collisions, but at the same time remained a simple and humble man who liked to enjoy the little pleasures of life. He was not taking himself or his work too seriously, while still being very serious and rigorous about his work.

We first got to know Oleg at the physics department, before he quickly became our friend. We enjoyed discussing and laughing with him, and it was simply nicer to go to work when Oleg was around. Perhaps it is less known that Oleg had a great sense of humor, but one could really fully appreciate it once knowing him better. Often, I could hear from my office Samantha and Oleg laughing and having long and loud discussions about physics, teaching, and life in general. Oleg had a unique and charismatic personality; even if he was not the most talkative person, his presence in a room could immediately be felt. Oleg could be strict with his students and post-docs, requiring a high-level of efforts and rigor, the same he was also imposing on himself.

Unfortunately, I never had the opportunity to collaborate with Oleg, as I was working on different projects with Klaus at the time. Nevertheless, as time passed, we got interested with Samantha to learn more about the BSR code. Oleg gave us his writeup [15] and review paper [16], and he was always available to answer any of our questions and explain the subtleties of the code. Before coming to Drake, we had worked on photodetachment of molecular anions, and we knew too well the difficulties and hard work to obtain accurate cross sections when employing a single set of orbitals to describe simultaneously the anion and the neutral molecular states. Therefore, we could appreciate even more the flexibility of the atomic BSR code, which could easily circumvent these issues by allowing sets of orbitals optimized for each atomic state. In 2016, I also remember Chris Greene specifically stopping in Des Moines during a road trip to discuss possible calculations on a complex atomic system for cold-atom physics, which could only be performed accurately using the BSR code. This was another clear evidence to me at the time of the broad applicability of the BSR code, followed by Oleg's impressive research productivity during my time at Drake, which resulted in an astonishing number of publications.

As we were preparing to teach Computational Physics with Samantha at Rollins College, we asked Oleg for his course material. We were struck, not only by the interesting topics Oleg had put together for his class, but also by the level of rigor and high-level material he was using in his course. Clearly, any students coming out of Oleg's class would have learned a lot about the subject. Our current courses in Computational Physics at Rollins and Kennesaw State, which always received excellent feedback from students, are built for the most part from Oleg's material.

On numerous occasions we met Oleg and Tanya for social gatherings, barbecues, celebrations, and at conferences. We always had a great time. Oleg liked to prepare seasoned pork and drink Eastern European beers. He and I also shared a passion for football (the version called "soccer" in the US). He was a fan of "the blues" of Chelsea and could wake up on a Sunday morning at 6 a.m. to watch a game of his favorite team. After we left Des Moines, we still met Oleg and Tanya at conferences before COVID-19 hit.

Oleg was a great man and an amazing physicist. His legacy in atomic physics will live on for decades to come. We will dearly miss him.

\subsection{Hartmut Hotop (University of Kaiserslautern, Germany) and Michael Allan (University of Fribourg, Switzerland)}

We first became aware of Oleg Zatsarinny as a scientist in the mid-1990s when he cooperated with Werner Mehlhorn's group at Freiburg (Germany) on the decay of electronimpact excited metal atoms through Auger decay or autoionization along the lines developed at Uzhgorod with V. Lengyel. Later, in 2004, we were struck by two papers published in Journal of Physics B by Oleg and Klaus Bartschat, which described advanced calculations 
of electron-impact excitation of $\mathrm{Ne}$ and Ar, based on the novel B-spline R-matrix method. These papers held promise for a quantitative description of such processes, including stateresolved final states and sharp resonance features in the respective energy dependence. In view of the multitude of excited states and the richness of the resonance spectra of the rare-gas atoms, it was not obvious to what extent these promises would actually hold when confronted with the real life of highly-resolved experimental data in absolute cross sections units. Such results could be provided by the highly-developed electron-impact spectrometer in Fribourg, allowing energy resolutions down to $7 \mathrm{meV}$ and covering the full range of scattering angles from zero to 180 degrees. In Kaiserslautern, a laser-photoelectron apparatus allowed studies of resonances and excitation functions for long-lived states at energy widths down to $4 \mathrm{meV}$.

The first detailed comparison between theory and experiment was made for the excitation function of the two metastable $\mathrm{Ne}\left(2 \mathrm{p}^{5} 3 \mathrm{~s}\right)^{3} \mathrm{P}_{2}$ and $\mathrm{Ne}\left(2 \mathrm{p}^{5} 3 \mathrm{~s}\right)^{3} \mathrm{P}_{0}$ levels over the range 16.5-19.1 eV [17] (see Figure 6). The calculated cross section (obtained in absolute units) is in very good agreement with the experimental data (normalized to theory at the peak near $16.9 \mathrm{eV}$ ) with regard to the overall energy dependence as well as the detailed resonance structure. Even the very narrow resonance feature $\mathrm{E}$ (see inset; predicted width $0.8 \mathrm{meV}$ ) is detected as a weak peak experimentally (resolution about $5 \mathrm{meV}$ ).

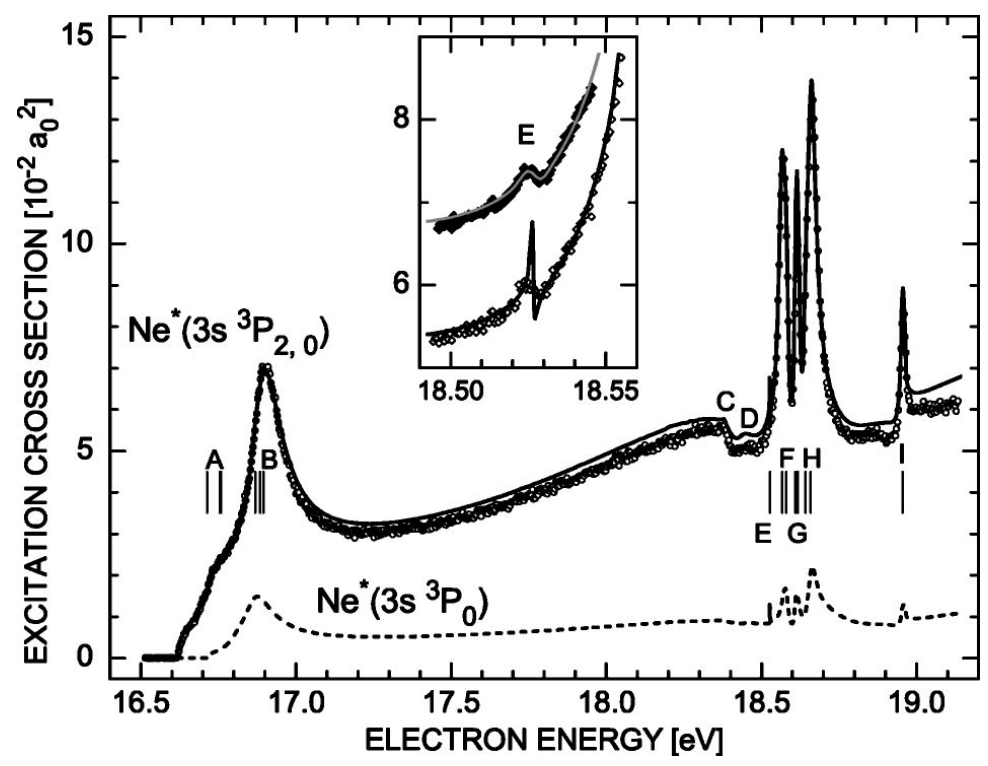

Figure 6. Excitation cross section (in units of $10^{-2} a_{0}^{2}$; $a_{0}$ is the Bohr radius) for the production of metastable $\mathrm{Ne}\left(2 \mathrm{p}^{5} 3 \mathrm{~s}\right)^{3} \mathrm{P}_{2,0}$ atoms in the energy range 16.5 to $19.0 \mathrm{eV}$. Open circles: measurement [17]. Full curve: B-spline R-matrix theory [including cascade contributions and assuming identical detection efficiencies for $\mathrm{Ne}\left(2 \mathrm{p}^{5} 3 \mathrm{~s}\right)^{3} \mathrm{P}_{2}$ and $\mathrm{Ne}\left(2 \mathrm{p}^{5} 3 \mathrm{~s}\right)^{3} \mathrm{P}_{0}$ atoms]. Broken curve: theoretical excitation function for the production of $\mathrm{Ne}\left(2 \mathrm{p}^{5} 3 \mathrm{~s}\right)^{3} \mathrm{P}_{0}$, including cascade contributions. Inset: enlarged view of the data over the energy region $18.48-18.58 \mathrm{eV}$, revealing a narrow Feshbach resonance (see text).

Subsequently, more decisive tests of the theory were provided by angle-differential excitation cross sections for $\mathrm{Ne}, \mathrm{Ar}, \mathrm{Kr}$, and $\mathrm{Xe}$ in absolute units, measured with the Fribourg spectrometer. We show just one example, namely the excitation of the four lowest excited states in Ne from threshold to $20 \mathrm{eV}$, measured at the backward scattering angle $180^{\circ}$ with an energy width of $10 \mathrm{meV}$ for the incident electron beam. In Figure 7 we compare the respective experimental cross sections (left side) with those of the B-spline R-matrix calculations (right panels) [18]. Amazing agreement is observed in both the absolute size and in the detailed resonance structure, which shows characteristic changes for the four final excited $\mathrm{Ne}\left(2 \mathrm{p}^{5} 3 \mathrm{~s}\right)$ levels. We should note that we did not communicate the experimental data to Oleg and Klaus before we received their results. 

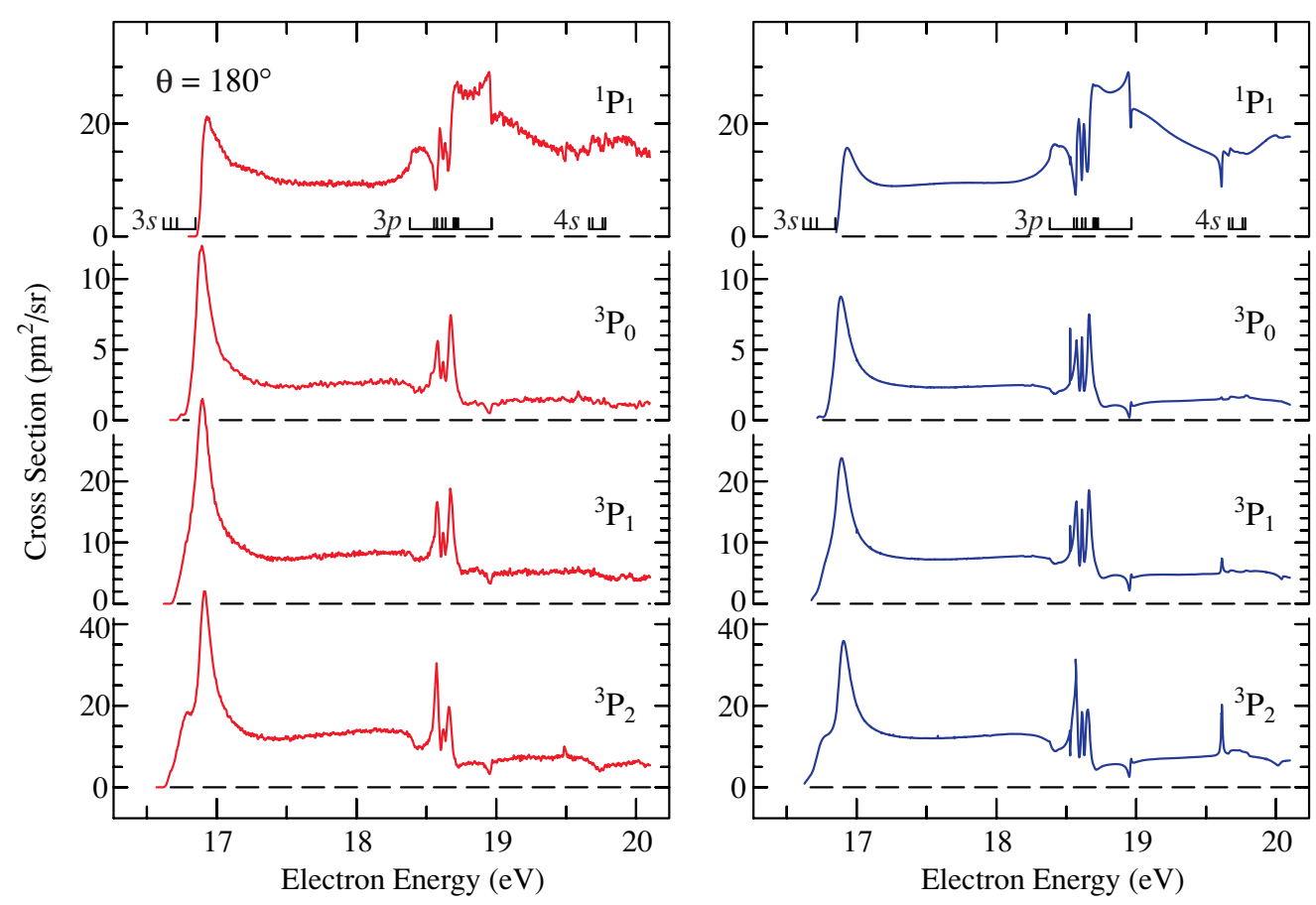

Figure 7. Absolute cross sections for excitation of the $\mathrm{Ne}\left(2 \mathrm{p}^{5} 3 \mathrm{~s}\right)$ states at $\theta=180^{\circ}$. The experimental data are in the left and the theoretical predictions in the right panel. Thresholds for the $2 p^{5} 3 s, 2 p^{5} 3 p$, and $2 p^{5} 4 s$ excitations are indicated below the top spectra. From [18].

In our view the development of the B-spline version of R-matrix theory has opened new horizons for the prediction of excitation cross sections for a broad range of atoms. Oleg played a very important role in this effort. It was a pleasure to interact with him, both as a scientist, who was patient with us experimentalists asking endless questions, and as a modest dear friend. We sorely miss him; our thoughts are with his wife Tatyana.

\subsection{Alexander Dorn (Max-Planck Institute for Nuclear Physics, Heidelberg, Germany)}

My first encounter with Oleg in 1994 was decisive for the scientific careers of both of us. I was a PhD student in the group of Werner Mehlhorn at the University of Freiburg when Oleg visited us. For the first time after the fall of the Iron Curtain between Eastern and Western Europe, he had the opportunity to cross this boarder and to collaborate with a group outside the former Soviet Union [19]. Already before Werner Mehlhorn had received Nikolai Kabachnik and Alexei Grum-Grzhimailo from Moscow State University and also established very fruitful collaborations with them. I learned how advanced theoretical physics in Eastern Europe and in particular in Russia was and that these scientists could analyze and interpret the atomic reactions that we were investigating experimentally very well. In particular I realized that these people, who allegedly were our enemies during the Cold War, are very warm-hearted and likeable. We quickly became friends.

It was just the time in my PhD project when, after commissioning a newly built apparatus, I had achieved to measure electron spectra for Auger and autoionization processes initiated by electron impact on laser-excited sodium atoms [3]. I had difficulties in interpreting the multitude of new lines and their intensities. Hence it was perfect timing that Oleg had just managed to perform highly accurate calculations for part of the observed states [1]. The challenge for theory was that the configurations such as $\left(2 p^{5} n_{1} \ell_{1} n_{2} \ell_{2}\right)$ involved three open shells and significant electron correlation. Oleg realized that a large part of the correlation was due to the core polarization by the valence electrons and could be well accounted for by using a model core-polarization potential in the Hamiltonian. Therefore, the state energies obtained by his configuration interaction calculation were impressively accurate, with deviations from experiment of not more than $10 \mathrm{meV}$. Oleg, 
Nikolai, Alexei and I analyzed and interpreted the measured electron spectra concerning line intensities and anisotropies. This resulted in my very first scientific publication, on which Oleg was the last author [20]. Naturally from this time onward we had regular and very successful collaborations.

For our more recent joint studies, the B-spline R-matrix code (BSR) [15], which Oleg developed much further after he moved to Drake University collaborating with Klaus Bartschat, was decisive. Using BSR, Oleg and Klaus obtained fully differential cross sections (FDCS) for electron-impact ionization of atomic targets heavier than helium for comparison with data from our $(e, 2 e)$ experiments in Heidelberg. In order to critically test theory, we had chosen rather challenging systems, including low energies of the initial- and final-state continuum electrons and non-trivial multi-electron targets like argon. It turned out that the BSR results were impressively accurate not only in shape but also in the magnitude of the FDCS. The calculations were so reliable that the differences of the FDCS magnitude between experiment and theory observed in some cases were eventually considered to point to an experimental flaw rather than to a shortcoming of the theoretical model. Indeed, for our initial argon FDCS data [21], a cross-normalization error was identified in the data analysis [22]. After the appropriate correction was made, the FDCS were in good agreement with the BSR results, as seen in Figure 8 [23].

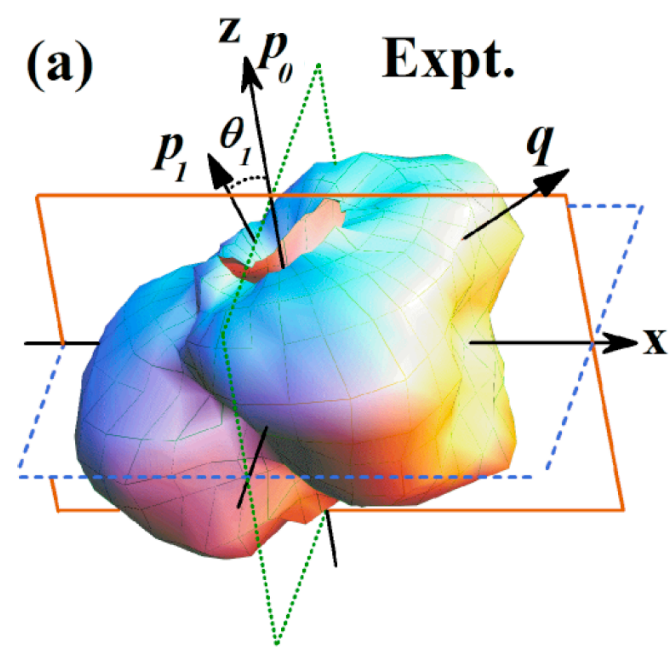

\section{(b) BSR}

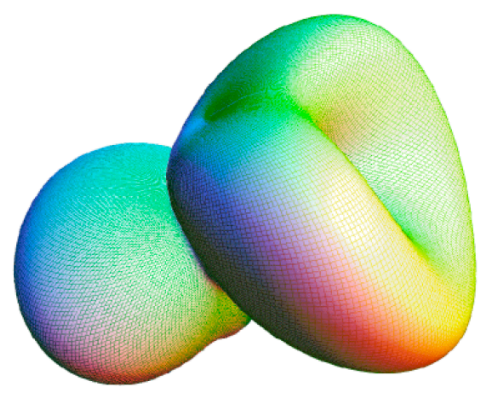

Figure 8. Fully differential cross sections for electron-impact ionization of argon covering almost the full $4 \pi$ solid angle for electron emission [23]. The projectile $\left(p_{0}, E_{0}=66 \mathrm{eV}\right)$ is coming in from below and scattered to the left $p_{1}$. The FDCS is plotted as a function of the emission angle of the electron ejected from the $\operatorname{Ar}\left(3 \mathrm{p}^{6}\right)$ subshell with kinetic energy $E_{2}=3 \mathrm{eV} . q$ is the momentum transfer vector. (a) Experiment using a Reaction Microscope. (b) BSR theory.

From my point of view Oleg was a genius in developing trackable solutions for principally untrackable complex many-body systems. Oleg had an excellent grasp of the underlying physical mechanisms. As a result, he and his collaborators in the recent decades strongly advanced electron-atom scattering theory. With Oleg I lost both a most helpful and supportive colleague and a good friend.

\subsection{Barry I. Schneider and Collin (Xiaoxu) Guan (National Institute for Science and Technology, Gaithersburg, USA)}

Other than meeting Oleg at various conferences, one of us (BIS) interacted with Oleg first as the NSF AMO Program Director in PHY, where I helped in securing some funding for Oleg via the ITR program. Then we both became collaborators with Klaus, Johannes Feist, and the late Cliff Noble on some problems in attosecond dynamics. The basic idea was to use the BSR program to construct required Hamiltonian and dipole transitions matrix elements and then to use those and the propagation techniques Collin, Johannes and I had developed, to propagate the TDSE and extract the transition matrix elements. 
The first calculations were for single ionization of Ne [24]. These were then extended to the Ar [25] atom, as shown in Figure 9. Somewhat later, the BSR dipole matrix elements were used to look at the time delays in the $\mathrm{Ne} 2 \mathrm{~s}-2 \mathrm{p}$ photoionization process [26].

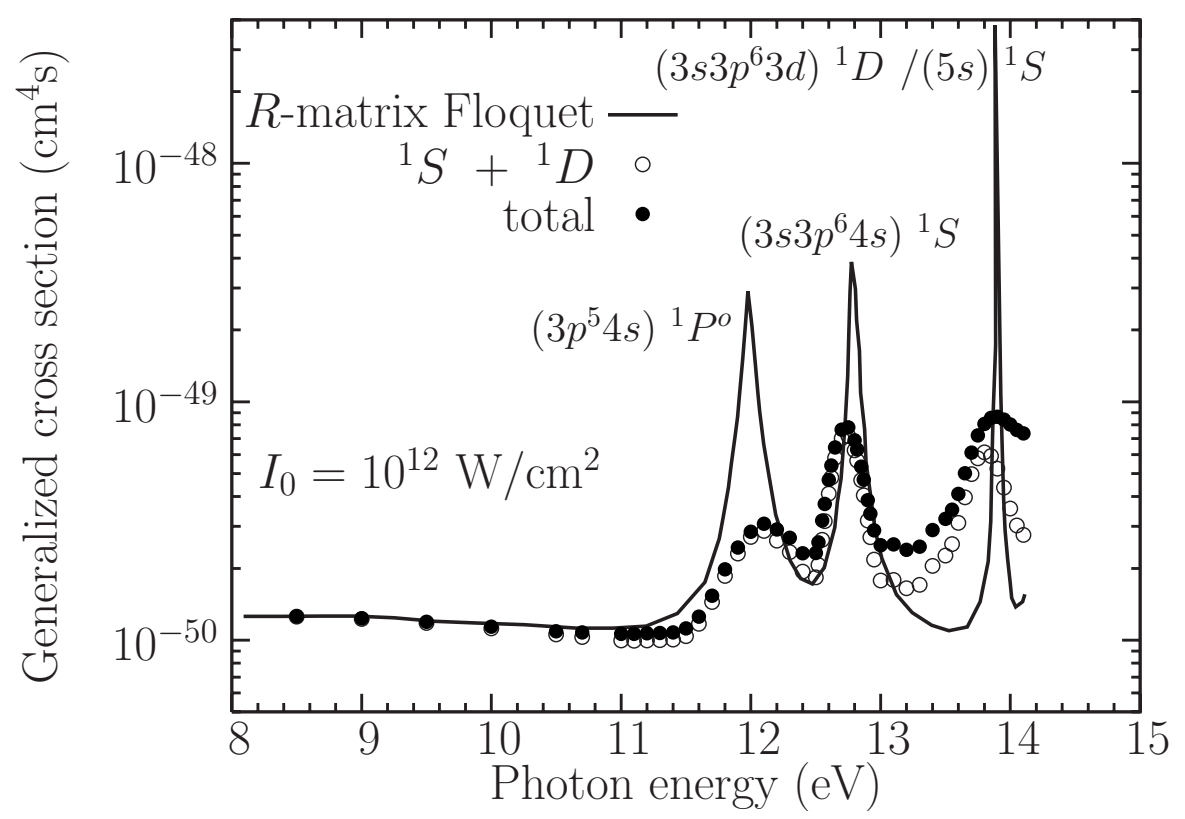

Figure 9. Generalized cross section for two-photon ionization of $\operatorname{Ar}\left(3 p^{6}\right)^{1} S$ as a function of photon energy [25]. A 30-cycle laser pulse with a peak intensity of $10^{12} \mathrm{~W} / \mathrm{cm}^{2}$ was used in the calculations. The filled circles represent the results obtained by using the total ionization yield, while the open circles show those generated by summing up the partial ionization yields from the individual channels. The Floquet results are from McKenna and van der Hart [27].

All of these collaborations were successful both intellectually and personally. Oleg was always there to help, although at times we had to prod him a little since his first love, using BSR to compute very precise electron scattering and photoionization cross sections, were always uppermost in his priorities. But, all in all, he was an excellent colleague, and clearly an outstanding contributor to pushing the frontiers of computational AMO physics. The numerical advances of the BSR method have made it the approach for highly accurate calculations in atomic collision physics, and that is likely to continue for a long time to come. He is already missed.

\subsection{Yuri Ralchenko (National Institute for Science and Technology, Gaithersburg, Maryland, USA)}

Although both Oleg and I spent six years (nowadays it is a combined B.Sc. and M.Sc. program) studying at the Moscow Institute of Physics and Technology, we never met there since he graduated the same year I was accepted. So it took quite a few more years for us to meet. Charlotte Froese Fischer joined our Atomic Spectroscopy Group at NIST around 2005 and Oleg's name started to come up very frequently in our conversations on atomic physics. Frankly, I was already familiar with his recent papers on accurate calculations of atomic parameters such as level energies, oscillator strengths, and collisional cross sections, and I was sincerely impressed by their quality. Soon we started meeting Oleg and Tanya rather regularly at APS DAMOP, ICPEAC and other conferences around the world. From the very first encounter onwards we had many exciting and entertaining conversations touching on our Ukrainian origins, current political events, our alma mater, family immigration issues and many, many others including of course Oleg's passion-soccer. And what a passionate fan he was... In the summer of 2008 Oleg visited our group for a few weeks that partially overlapped with the UEFA Championship. Needless to say, on the game days he was almost dragging me home from NIST to watch the late afternoon games! 
But physics was always the priority. Oleg's numerous papers are well known and highly cited. For me personally, his extensive work on application of B-splines in atomic physics was an example of a virtuoso tour de force that will resonate for many years. His accurate results serve as true benchmarks; atomic physicists and plasma spectroscopists use them extensively. Strangely, we only published one joint paper [28]. Yet on many occasions we discussed various physical problems and sometimes did quick simultaneous calculations, he at Drake and I at NIST, to answer any unresolved questions.

Oleg was a unique researcher and an extraordinary human being-humble, delicate, yet very spirited in everything related to physics. It was a privilege to know him personally and to learn a lot from him. This is something that I will cherish forever.

\subsection{Yang Wang (Harbin Institute of Technology, Harbin, People's Republic of China)}

I first met Oleg at Drake University in April 2012, when I entered Klaus Bartschat's group as a visiting scholar. In the following year, we worked together on the problems of electron scattering from atomic targets including carbon [29], lead [30] and chlorine [31]. That was one of the most important periods in my scientific life. During that time, I learned a lot from Oleg and Klaus, especially about the novel B-spline R-matrix method. Oleg was always very patient in answering all my questions, and he showed me the details of how to improve the calculations by producing better target wave functions and how to use the many parameters in his programs.

We maintained our collaboration after I returned China. We had performed calculations of electron impact on nitrogen [32], argon [33] and most recently $\mathrm{Xe}^{+}$to set up a collisional-radiative plasma model [34,35]. Although there is an 11-hour timeshift between China and the central US, we still communicated effectively. Oleg always replied as soon as he could. Actually, the time difference often made our work more effective since we could deal with the problems during our own day time. This was particularly true when we worked on the accurate description of the target states. The generation of accurate target wavefunctions required plenty of time and patience. Working in shifts moved our work continuously forward, especially when we were struggling with the problems of orthogonal conditions and target overlaps. Oleg was always strict with these issues to ensure the accuracy of the calculations.

In addition to his dedication to scientific research, Oleg also devoted himself to teaching. He taught "Computational Physics" when I was at Drake University. The course was not easy for the students, but would let them learn a lot if they really followed his lead. Oleg prepared plenty of examples to show the methods and corresponding codes. When students came to his office with questions, he would always be patient to help them out. Once a student came with a Fortran code that looked the same as the example but did not compile successfully. After a long time checking, Oleg finally helped her to find the bug, which turned out to be a missing carriage return in the very last line!

Oleg was friendly, gentle and supportive in life. He, as well as Klaus Bartschat and Xiaoxu (Collin) Guan, provided a lot of help during my stay in Des Moines. They often drove me to the supermarket for shopping since I didn't own a car at that time. That actually made my life in the US much easier. I still remember the happy hours we got together at Oleg's or Klaus' house with many friends (see Figure 10). Oleg liked holding a bottle of beer and talking to us. He and his wife Tatyana were a happily married couple. Oleg and I met several times after I left Des Moines, mostly at the ICPEAC conferences. Tatyana was always there with him. I could feel their deep love for each other. Oleg mentioned several times that he wanted to buy a black pearl necklace for Tatyana as a gift. 


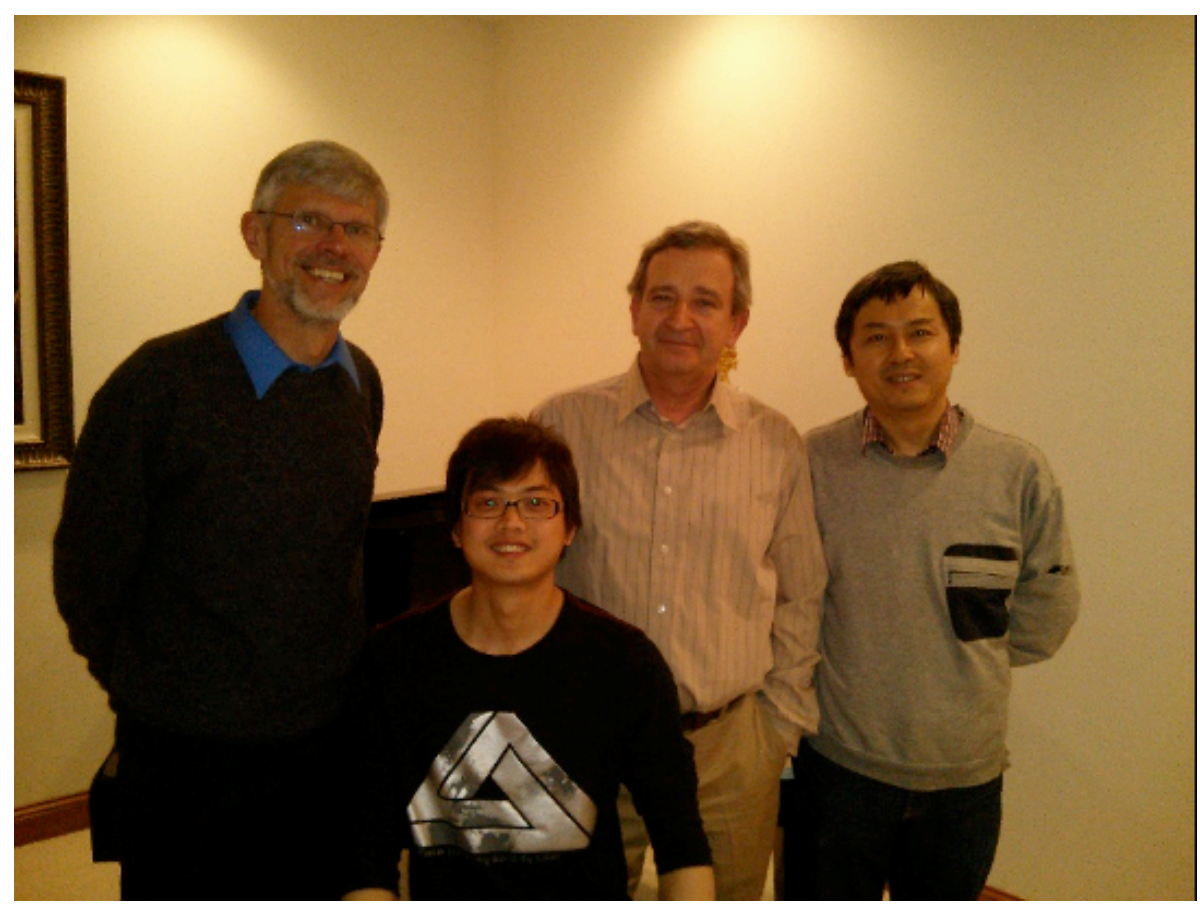

Figure 10. Photo of a get-together before I left Des Moines in 2013. Photo from the private collection of Yang Wang.

Oleg's departure is a huge loss for his family, friends and the community of atomic physics. His kind soul, sincerity and scientific spirit will stay with us forever.

\subsection{Kedong Wang (Henan Normal University, Xinxiang, People's Republic of China)}

I met Oleg when I attended his lecture at the ICPEAC 2013 in Lanzhou. That's when I began to know about the work in theoretical atomic physics conducted by Klaus and Oleg at Drake University.

In 2014, I obtained funding from the China Scholarship Council (CSC) and thus had a one-year visiting opportunity to study and research at Drake University beginning on 1 September 2015. With the help of Klaus and Oleg, I adapted myself to the new situation quickly. One day there was something wrong with my laptop. Oleg spent the entire afternoon to help me purchase a new one. He was always ready to help others. During this time, Oleg taught me electron-atom scattering theory and how to use his B-spline R-matrix code. We obtained accurate cross sections for electron-impact excitation and ionization of atomic boron [36,37] and gallium [38], as well as photodetachment cross sections of their negative ions.

Oleg and his wife Tatyana were very kind. On some week-ends, they took me to visit Pella City, Omaha Zoo, and other places nearby. In autumn, they drove me to pick apples in Ames. Sometimes they invited me to spend time at their house, where Tatyana cooked delicious food. Many thanks to Oleg and Tatyana-I had a great time that one year in Des Moines.

After I returned to China in August 2016, we kept in contact with each other. In July 2017, I invited Oleg and Tatyana to visit China. As seen in Figure 11, they enjoyed their time in my home country. We discussed further calculations on electron collision with $\mathrm{Mg}^{4+}$ [39], and we tried to identify possible reasons for some major discrepancies between the B-spline R-matrix (BSR) [40] and Dirac Atomic R-matrix Code (DARC) [41] predictions. 


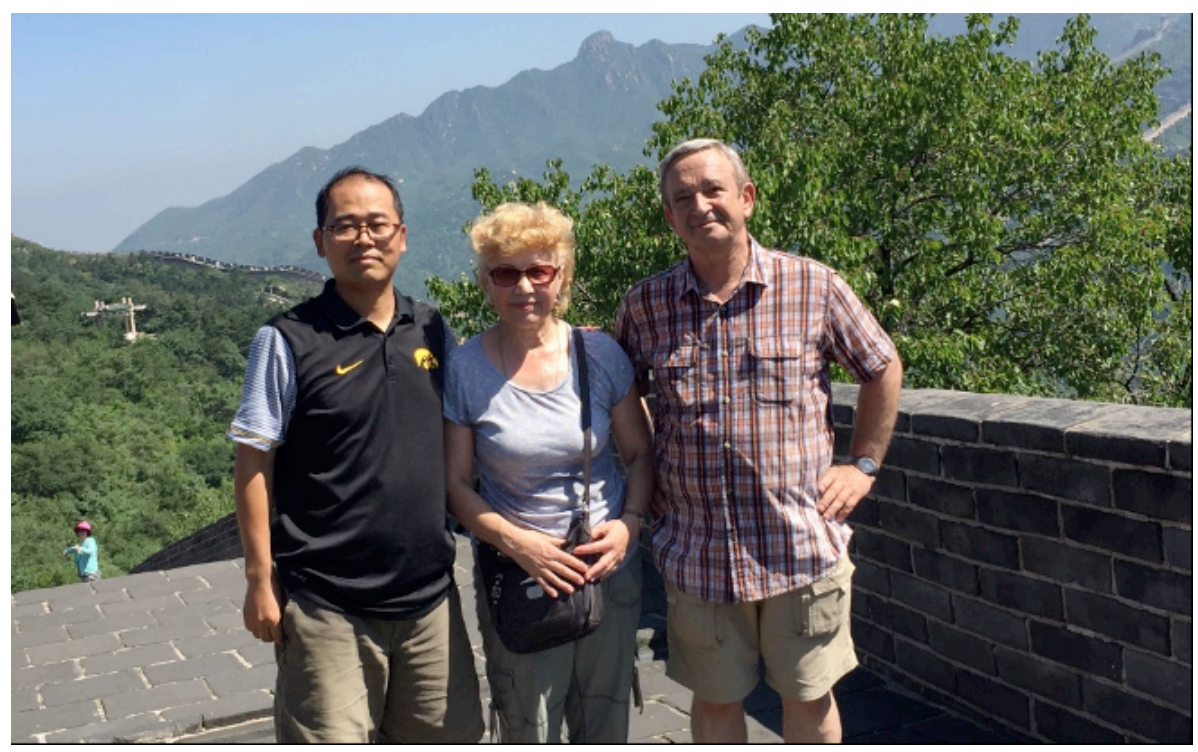

Figure 11. Kedong Wang (left), Tatyana Zatsarinny (middle) and Oleg Zatsarinny (right on the Great Wall in 2017. Photo from the private collection of Kedong Wang.

Oleg was munificent to share his programs with us, and hence my colleagues also benefited from his B-spline codes. Subsequently, we reported extensive calculations for electron collisions involving a wide range of transitions in Fe [42]. These results allow a more detailed analysis of the measured spectra from various space observatories and the nonlocal thermodynamic equilibrium modeling of late-type stars [43]

The last time we met in person was at the 2019 ICPEAC in France. At that time we talked about our plans to invite him to visit China again and do some further work developing the BSR code. Unfortunately, all these plans were broken by the news that Oleg had passed away. I lost a good friend and a valuable guide on my road of research.

\subsection{Zhangjin Chen (Shantou University, Guangdong, People's Republic of China)}

The first and only time I met Oleg in person was in the summer of 2013 at the XXVIII ICPEAC in Lanzhou, China. I still remember clearly that a smiling man walked towards me while I was standing by my poster, on which I had put Oleg's name below a figure that showed the total cross sections for electron-impact excitation of $\mathrm{Ar}^{+}$, showing the calculations he had performed for me. The man stopped in front of me, pointed at the name "Oleg Zatsarinny" on the poster, and then said to me with some surprise in his voice: "Oh, my name is there!" His kind and positive demeanor instantly put me at ease. It's a great pity that I did not get the chance to invite Oleg to visit Shantou University.

My collaboration with Dr. Oleg Zatsarinny and Prof. Klaus Bartschat at Drake University can be traced back to 2010 when I was at Kansas State University. In the past 10 years, I have been focusing on the development of a quantitative rescattering model for laser-induced nonsequential double ionization (NSDI). For this purpose, accurate cross sections for both excitation and ionization of singly-charged ions by electron impact are highly desirable. It was Oleg who carried out the B-spline R-matrix calculations for all the results we needed, and we greatly benefited from his contribution. Oleg was always prompt in his response to all my requests-except for one time about two years ago, when he wrote to me "just an unexpected thing happened (connected to health)". I did not suspect at the time that it was a serious condition because his work for our collaboration had continued on as usual.

In recent years, we have made substantial progress in NSDI with Oleg's help. We published 8 papers in Physical Review A and Optics Express with his co-authorship. One example is shown in Figure 12. I believe that his contribution will remain impactful to our research for years to come. 

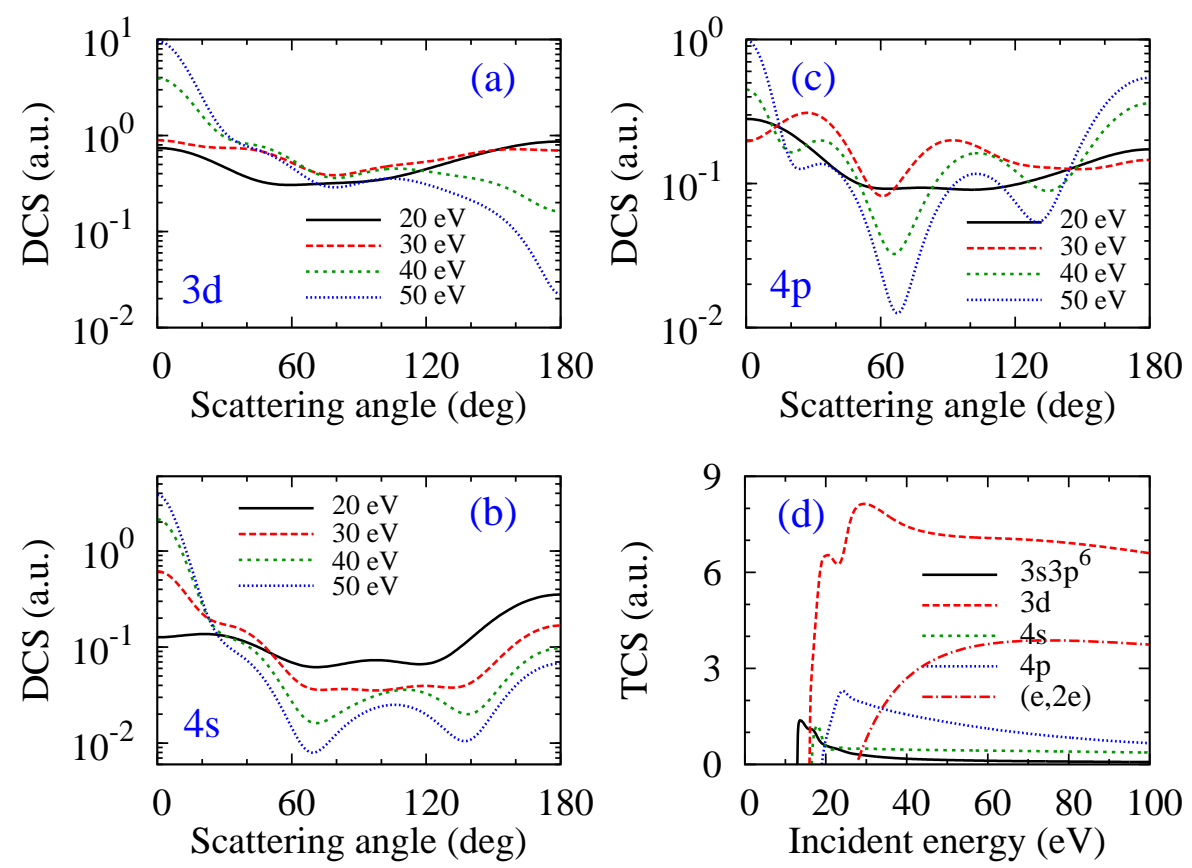

Figure 12. Differential cross section for electron impact excitation of $\mathrm{Ar}^{+}$from the ground state $3 s^{2} 3 p^{5}$ to the excited states with configurations $3 s^{2} 3 p^{4} 3 d(\mathbf{a}), 3 s^{2} 3 p^{4} 4 s(\mathbf{b})$, and $3 s^{2} 3 p^{4} 4 p(\mathbf{c})$ at incident energies of 20,30, 40, and $50 \mathrm{eV}$, respectively. In panel (d), the total cross sections for electron impact excitation of $\mathrm{Ar}^{+}$to the excited states with configurations $3 s 3 p^{6}, 3 s^{2} 3 p^{4} 3 d, 3 s^{2} 3 p^{4} 4 s$, and $3 s^{2} 3 p^{4} 4 p$ and electron-impact ionization of $\mathrm{Ar}^{+}$from the ground state are also displayed. For excitation, all results were obtained with the BSR code. For ionization, the total cross sections were calculated by using the semiempirical formula of Lotz [44]. From Chen et al. [45].

\subsection{Igor Bray, Dmitry Fursa, and Alisher Kadyrov (Curtin University, Perth, Australia)}

Oleg Zatsarinny made a truly remarkable contribution to the development of computational methods in atomic physics with a reformulation of the R-matrix method. The use of B-splines and non-orthogonal orbitals led to increased flexibility and accuracy of the method and, consequently, to applications to many complex atoms with spectacular results. For many complex atomic and ionic targets, Oleg's results are the only available large-scale close-coupling calculations and will be the accuracy benchmark for many years to come.

Our research group use an alternative formulation of a close-coupling method: a momentum-space formulation known as the Convergent Close-Coupling (CCC) method. The available CCC computer code is not as general as the R-matrix formulation Oleg has developed, but for relatively simple atoms both calculation techniques should lead to the same cross sections. Indeed, it proved to be an extremely powerful demonstration that two very different implementations of the close-coupling method, with very different target wave functions and techniques to account for collision dynamics, lead to practically the same cross sections. A representative example is shown in Figure 13 taken from our joint investigation of electron-beryllium scattering [28]. This provides confidence in the theoretical results and allows to address the important issue of uncertainty estimates [28]. 


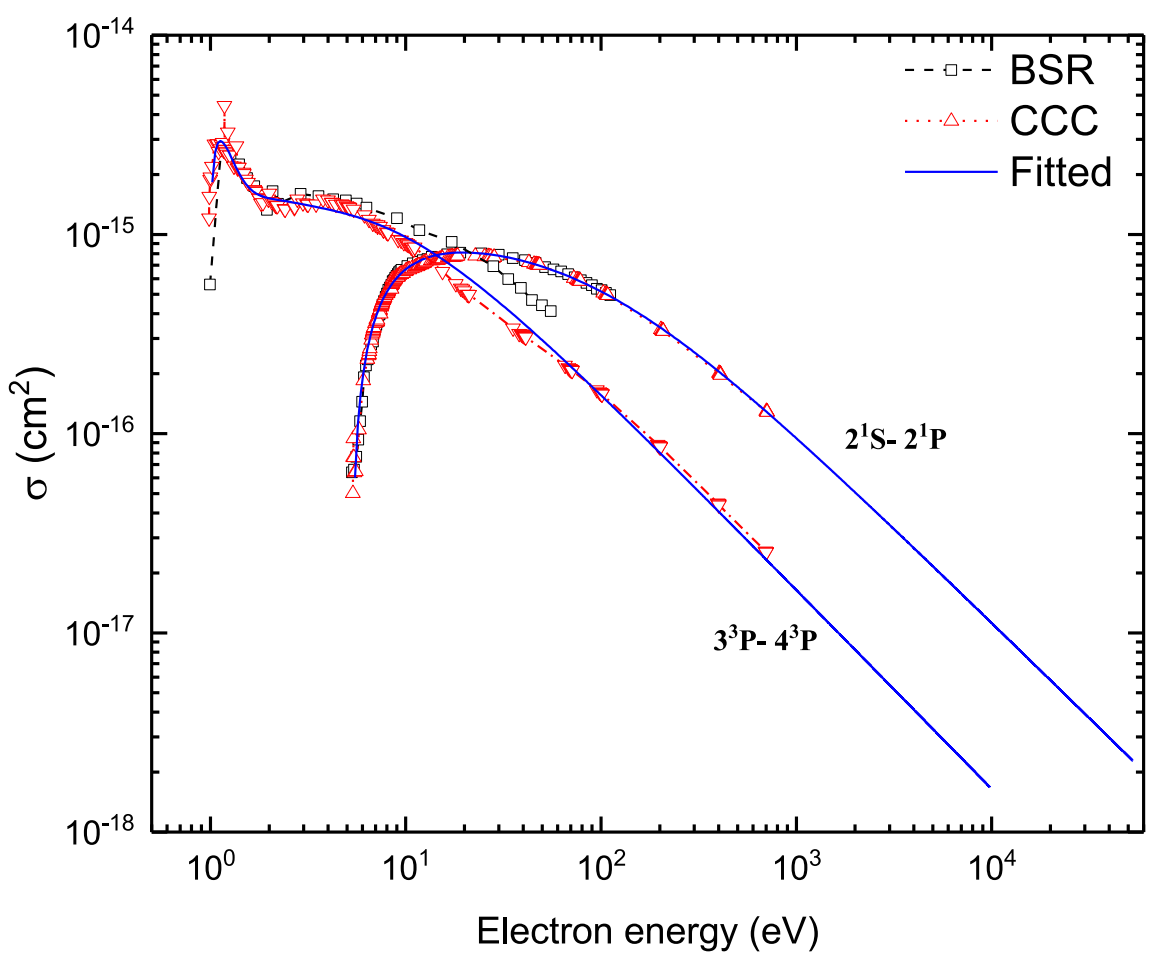

Figure 13. Electron-impact excitation cross sections for the dipole-allowed $\left(2^{1} \mathrm{~S} \rightarrow 2^{1} \mathrm{P}\right)$ and dipoleforbidden $\left(3^{3} \mathrm{P} \rightarrow 4^{3} \mathrm{P}\right)$ transitions in neutral beryllium. Dashed lines with squares, dotted lines with triangles and solid lines represent BSR, CCC and fitted results, respectively [28].

We started to collaborate with Oleg when he joined Klaus Bartschat at Drake University. Over the years there were many emails from Oleg, many joint projects and papers, conferences attended together, and many conversations about physics and life in general. Oleg visited the Curtin group in November 2013 to advise on a new project for reformulation of the CCC method to a more general foundation with the aim to produce a general-purpose computer code applicable to a wide range of targets. As it often happens, the celestial bodies should align themselves accordingly for a project to succeed, and this alignment happened only a few years back with a PhD student working now on this project. At our request, Oleg prepared several computer programs and advised us on various aspects of their use. The last email from Oleg came on 20 December 2020. It was such a shock to learn that he passed away just a few weeks later. We remember Oleg as a great scientist, very approachable, happy to help, and generous in passing his knowledge and experience to colleagues all over the world.

\subsection{Anatoli Kheifets (Australian National University, Canberra, Australia)}

Oleg Zatsarinny was a long-time friend of mine. We shared a similar background of being educated in Theoretical Physics in the early 1970s in the former Soviet Union and then getting professional employment in the West. While we worked on different continents, we often met during international Atomic Physics conferences, most regularly at the ICPEAC meetings starting from Belfast in 2011 and then in Toledo in 2015 and Cairns in 2017. The Cairns meeting was particularly eventful, as I served as a local host and could introduce Oleg and his wife Tanya to the wonders of the Australian hinterland. Figure 14 show us taking a break during one of our excursions.

The last time I spoke to Oleg was at the 2019 ICPEAC in Deauville. In retrospect, I understand that Oleg was not at his best at the time, as he was already battling his illness. Nevertheless, he was cheerful and we exchanged our usual jokes. Sadly, we won't have a chance to do that again. I miss Oleg very much. 


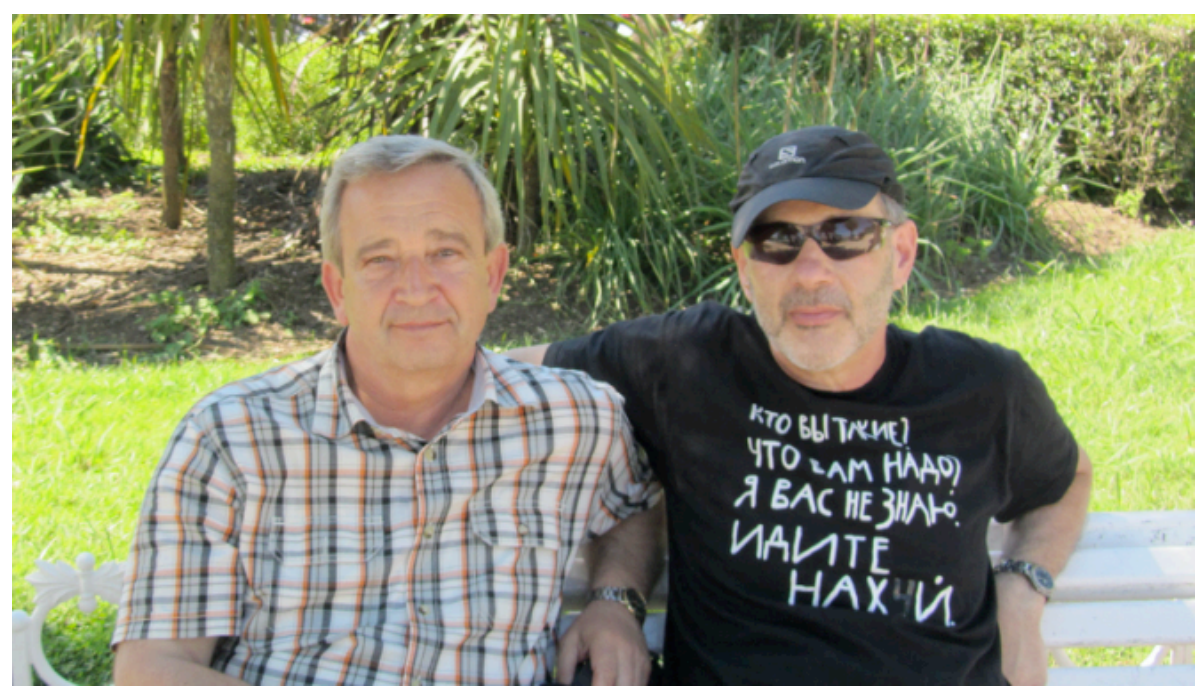

Figure 14. Taking a break from exploring the Australian hinterland. Photo from private collection of Anatoli Kheifets.

\subsection{Michael J. Brunger (Flinders University, Adelaide, Australia)}

Over many years, a joint theoretical and experimental collaboration, between Oleg and Klaus at Drake University and Peter Teubner and I at Flinders University, developed and prospered. Indeed, Peter used to refer to Oleg and Klaus as the 'dynamic duo', although I was never sure who he thought was 'batman' and who he thought was 'robin'. Both Peter and I developed a genuine respect and affection for Oleg the scientist and Oleg the human being. He was a very modest man, as our collaboration with he and Klaus grew over the years, and we both benefited from the collegiality that Oleg showed towards us. Oleg was always very responsive to our queries and was at pains to elucidate to us any of the underlying physics that he thought Peter and I might have been missing or were not quite on the right wavelength with. We always appreciated and learned from his advice.

Perhaps my favorite Oleg anecdote, that always makes me smile when I think of it, is attending some conference (this happened countless times) - GEC or DAMOP-in the USA and starting a conversation with him near the lecture theatres or posters, only to find that after a short period of time I was being manoeuvred outside so that he could have a smoke or three !! If I had a quarter for every time that scenario played out, then I'd be a wealthier chap for sure.

Vale Oleg Zatsarinny, you are being missed.

\subsection{Swaraj Tayal (Clark Atlanta University, Atlanta, Georgia, USA)}

In the late 1999 I advertised for a Post-Doctoral Research Associate position in Physics Today to work for my NASA research grant from the Planetary Atmospheres program. Oleg applied for the position. His research work and a strong letter of recommendation from Professor Charlotte Froese Fischer got my attention right away, and I offered him the position. Oleg came to Clark Atlanta University in early 2000. I met him for the first time at the Atlanta International Airport, where I went to pick him up. I still remember that he was wearing a badge with his name on it from some conference to assist me in recognizing him. It was smart thinking. I dropped him and his wife Tatyana to their hotel room that we reserved for their temporary stay until they could find a suitable apartment. I drove them around for the next 2-3 days to find a suitable apartment on the public transportation route.

We had a general discussion about the project work for a few days. It involved reliable calculations of cross sections for electron scattering from atomic oxygen, sulfur, and nitrogen. Oleg showed keen interest in the work and made suggestions on how we might proceed. He already had experience with the Belfast R-matrix codes and had published a couple of papers using them. However, he expressed his desire to work with a new R-matrix code based on the use of B-splines and non-orthogonal orbitals. He was 
already developing such codes and was very confident that he could make them work. I was a little hesitant at the beginning, but his understanding of atomic physics and his level of confidence encouraged me to give a try to something new. We planned to begin with small calculations, so that the results could be checked against those obtained with the well-established Belfast R-matrix package. Oleg worked very diligently for the next several months (Figure 15 shows him in his office), and I was very pleased with the progress of the work. I was immensely impressed by his programming skills and knowledge of physics. He worked almost independently except for some weekly discussions. Oleg first completed the e-O calculations, and the first paper on these calculations was published in April 2001 in Journal of Physics B [46]. After that Oleg started the e-S calculations, resulting in another publication in the same journal [47]. These calculations were very well received in the atomic physics community. When I met Professor Phil Burke, my postdoctoral research advisor from the Queen's University of Belfast, at the 2003 XXIII ICPEAC conference in Stockholm (Sweden), Phil showed keen interest in discussing the B-spline R-matrix method. I told him that these are new programs and Dr. Oleg Zatsarinny was the architect of these so-called "BSR" codes.

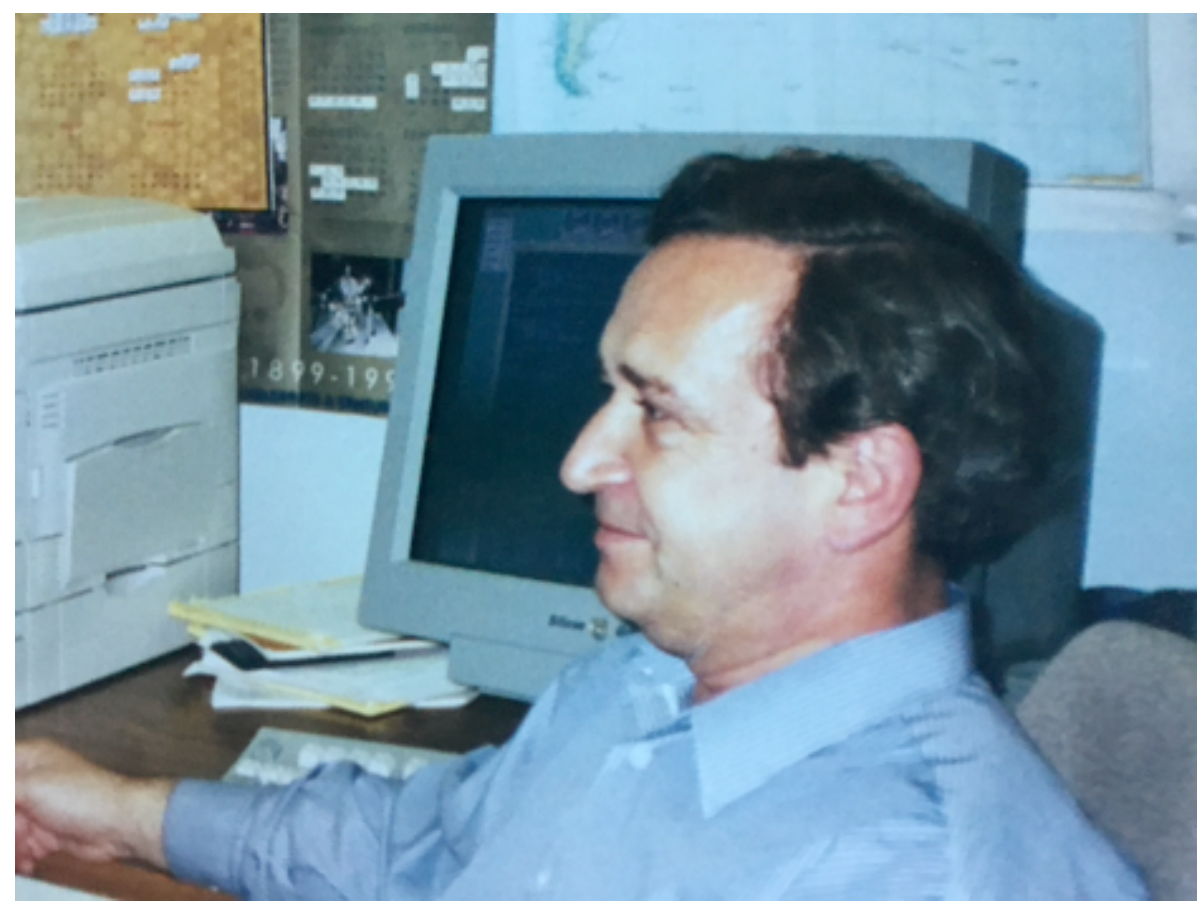

Figure 15. Oleg in his office at Clark Atlanta University 20 years ago. Photo from private collection of Swaraj Tayal.

Unfortunately, there were limited funds in the grant, and I had to break these bad news to Oleg. I decided to do it when there was still money to support him for another 2-3 months. It was a sad situation for both of us. Oleg worked with us at CAU for 15-16 months until about the end of the 2001 summer. Fortunately, Professor Tom Gorczyca at Western Michigan University had an open position around the same time, and he gladly hired Oleg. Even after Oleg left CAU we continued our interaction to complete work already in progress. Oleg was always there to help me selflessly in this work. Then, around 2005-2006, we mutually agreed to include Oleg as a paid External Consultant/Collaborator, first in multiple NASA and then in a recent NSF project. At the beginning of his new role, I invited him to Atlanta 2-3 times and later realized that it is much more efficient and cost effective to interact electronically and run the project work remotely. Oleg served as External Consultant on my NASA and NSF grants for almost fifteen years until the end of 2020. He would always do his part with the same diligence and passion that I witnessed when he was here at CAU. 
Oleg was very dependable and passionate about the research work. During this period, we collaborated on electron scattering from and photoionization of several neutral and lowly-ionized targets of particular relevance for astrophysics. One of these calculations, on photoionization of Sc, is written up as a full paper in this Special Issue honoring Oleg's legacy [48].

When I shared a draft of my next NSF proposal to Astronomy and Astrophysics program on the iron-peak elements $\mathrm{Fe}^{+}, \mathrm{Cr}^{+}, \mathrm{Ti}^{+}$, and $\mathrm{Sc}^{+}$with him, Oleg made some helpful suggestions and told me that further modification of the BSR codes would be required to carry out this work, which he would gladly do when the proposal was funded. Oleg also helped me in the submissions of proposals to the NSF's XSEDE High-Performance Computational Program by providing scaling graphs of the BSR codes to secure computer time for the work.

I used to meet him often at American Physical Society meetings and international conferences, where he could always be seen with his wife Tatyana. We talked a lot about physics but also spent some time going around to have a good time. The last time I met him was at the DAMOP meeting in Ft. Lauderdale in the Summer of 2018, where we presented our collaborative research on e-Fe ${ }^{+}$and $\mathrm{e}^{2}{ }^{2+}$. He was healthy and energetic at that time. At the 2019 ICPEAC in France (I could not make it to this meeting) he presented our collaborative work on $\mathrm{e}-\mathrm{Cr}^{+}$calculations. He continued working as a Consultant on the NSF grant even when he was having health issues. I sent him an e-mail on 17 February 2021, inquiring about his health. He replied within a day as usual and was still thinking about research. I wrote back that he should first take care of his health. Oleg's e-mail made me suspect that he was having serious health issues, but I never thought that it would be our last communication. Oleg was truly a dedicated scientist, humble colleague, and above all a superb human being.

\subsection{Leanne Pitchford (University of Toulouse, France, on Behalf of the LXCat Team)}

The significant progress made over the past decade by Oleg Zatsarinny and his collaborators in high-accuracy calculations of electron-atom scattering cross sections is of considerable interest to the Low Temperature Plasma (LTP) community, where modeling plays a critical role in the optimization of plasma-based applications.

Examples of such applications include plasma processes for etching and deposition on surfaces in the context of microelectronics, and, more recently, the development of plasma sources for applications in medicine, but there are many others. There is a huge variety of configurations and operating conditions used to generate LTPs, but in general, the degree of ionization is quite low and the behavior of the charged particles is controlled to a large extent by their collisions with the neutral background gas. Most of the energy gained by the electrons in the electromagnetic fields sustaining the plasma is deposited in the gas in the form of excitation, dissociation, and ionization, whereas the energy gained by the ions in the EM fields is mainly converted to gas heating or is transferred to the surfaces. The energy gained by the ions in the fields, mainly in the sheaths near the surfaces, is converted to gas heating or is transferred to the surfaces. Thus, for many applications, modelers are mainly interested in the electron component of the plasma.

In most LTP configurations, the electron energy distribution function (EDF) is nonMaxwellian and can be calculated by solving the Boltzmann equation using as input a "complete" set of electron/neutral scattering cross sections. This means that the cross section set must account for all important electron energy and momentum exchange processes in collisions with ground-state neutrals. Electron transport and rate coefficients are various weighted averages over the EDF. Such coefficients can be measured as functions of $\mathrm{E} / \mathrm{N}$ (ratio of electric field strength to neutral density) in homogeneous electric fields and for very low degrees of ionization and excitation. These coefficients can be measured very accurately, but when measurements are not available or when $\mathrm{E} / \mathrm{N}$ is no longer a good parameter (e.g., E-fields rapidly varying in time and/or space) recourse must be made to calculations that require a complete set of cross sections as input. Modelers are thus 
faced with the challenge of compiling a complete set of cross sections based on available measurements and theory, and yet consistent with the available measurements of transport and rate coefficients for each component of the gas mixture.

The contributions of Oleg Zatsarinny have been very significant in this context, especially for complex targets such as the heavy noble gases and open-shell systems. Oleg and his colleagues published and made data tables available on the LXCat website [49], which is a platform for curating data needed for modeling the charged particle components of LTPs. Thus, the LTP community has easy access to many of their excellent electron scattering data. Their calculated sets of cross sections in neon and in argon, for example, when used as input to a Boltzmann solver, yield transport and rate coefficients in excellent agreement with measurements over a wide range of $\mathrm{E} / \mathrm{N}$. While the data needed for complete sets generally include elastic momentum transfer and total cross sections for the inelastic and ionization processes from the ground state, the quantum calculations yield much more information and hence allow examination of common approximations made in Boltzmann solvers regarding anisotropic scattering and the importance of collisions with excited states.

\subsection{Luis L. Alves (University of Lisbon, Lisbon, Portugal)}

My contacts with Oleg were sporadic, but productive enough to demonstrate the importance of preserving his legacy and recognizing that his passing is a huge loss for Physics. I report a short episode, which occurred in 2014. At that time, I was looking for electronimpact cross sections with nitrogen atoms, for the modelling of $\mathrm{N}_{2}-\mathrm{O}_{2}$ discharges. I first contacted Klaus Bartschat about this, who answered:

Dear Luis,

Well, believe it or not, but we actually did this calculation already and published the results recently. I am attaching the PDF file of our paper. I'll also CC Oleg Zatsarinny on this reply. He can probably send you the numerical results, so you don't have to take them from the graph.

Best wishes,

Klaus

Two hours later, I received a message from Oleg with all the raw data of calculations for $\mathrm{e}-\mathrm{N}$ cross sections, in a $3 \mathrm{MB}$ compressed file, with the following message:

Dear Luis,

Attached is archive of our last results for the e-N problem. It includes also the momentumtransfer cross sections you are interested in ( $m$ t-files, look in "read_me" for explanations) Hope this will help, Oleg Zatsarinny

This was Oleg, always extremely available!

\subsection{Anna Dzarasova (London, United Kingdom, on Behalf of the Quantemol Team)}

The Quantemol team had known about Oleg's atomic R-matrix code for some time, and we were impressed with the implementation of B-splines and multiple levels of atomic physics it can account for. Once an opportunity arose and we had a relevant project, we invited him to come over to London and training our PhD student at the time, James Hamilton (seen right Figure 16). Oleg also gave a seminar at the UCL group meeting of Prof. Tennyson and interacted with various scientists in the group during this visit. 


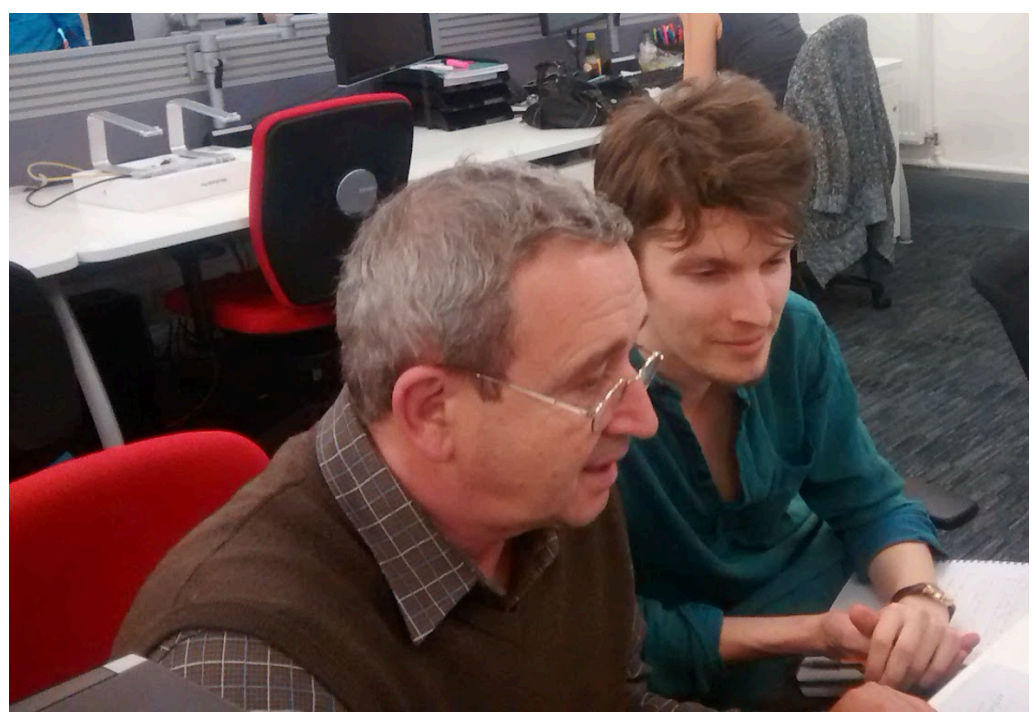

Figure 16. Oleg Zatsarinny (2012). Photograph from private collection of Anna Dzarasova.

He helped James with calculations of cross sections for iodine atom, which later on were used in modelling for iodine powered space thruster. Modelling of plasma using data resulting from this visit contributed to preparing the thrusters to be actually launched in orbit in 2020. The results were used for an associated publication Grondein et al. [50]. We have also revisited and improved on these calculations in the most recent work prepared by Ambalampitiya et al. [51].

Oleg's important contribution to the scientific community lives on not only in his sophisticated codes but also in many projects that benefited from them.

\subsection{Paul Barklem, Anish Amarsi, and Jon Grumer (Uppsala University, Uppsala, Sweden)}

Our interactions with Oleg started roughly a decade ago; P.B. had the opportunity to meet and talk with Oleg, at the ICPEAC conference in Cairns in 2017, and J.G. met him for the first time at the ICAMDATA meeting at NIST in Gaithersburg in 2012. We worked together on applying his calculations for electron collisions on various neutral atoms to astrophysical modelling (P.B., A.A.), and we had fruitful and motivating discussions as members of the same atomic structure community on multi-configurational methods (J.G.). In the first collaborative project, his calculations for excitation of $\mathrm{Mg}$ atoms by electron collisions [52] (and subsequent improvements)were key to improving our understanding of the $\mathrm{Mg}$ spectrum in stars and in supernovae ejecta, and set a solid platform for understanding the astrophysical production of $\mathrm{Mg}$, both through direct observation in supernovae and through the information on its history preserved in stars [53]. In particular, his calculations, coupled with convergent close-coupling calculations, showed that the data used up to that point for the very important intercombination transition $3 s^{2}{ }^{1} S-3 s 3 p{ }^{3} P$ at $457 \mathrm{~nm}$ had been significantly underestimated. The new calculations thus resolved a discrepancy where the $457 \mathrm{~nm}$ line in typical supernovae ejecta models with the expected roughly solar $\mathrm{Mg} / \mathrm{O}$ abundance ratios tended to be too weak compared to observations. We also worked and published together on applications of his data to other astrophysically important elements: oxygen [54], calcium [55], and potassium [56]. Oleg also selflessly shared his data and knowledge with others, declining co-authorship on principle in some cases, such as in the case of applications of his data to modelling carbon [57] and nitrogen [58].

Oleg's contribution to astrophysics through the development of the B-Spline R-matrix method and codes, used to calculate accurate data for electron processes on both simple and complex atoms, cannot be overstated. His work on the inelastic collisions of electrons with neutral nitrogen [32], carbon [29], oxygen [59], calcium [60], and iron [42], informs 
the statistical equilibrium modelling of the atmospheres of solar-type stars, and thereby the appearance of their emergent spectra. Improvements in the accuracy and reliability of detailed measurement of the chemical composition of the Sun [61], and in our understanding of the chemical evolution of our Galaxy[62,63], are a legacy of his work. The work on inelastic collisions of electrons with neutral iron, given the complexity of the species, is an especially important achievement for astrophysics where iron is the standard probe of the overall heavy-element content of stars in general.

\section{Conclusions}

As seen from the above testimonies, Oleg Zatsarinny's passing is a major loss for his family, his friends and colleagues, and science. We will miss his expertise and collegiality.

Author Contributions: Conceptualization, K.B.; collecting contributions, K.B.; writing first draft, K.B.; review and editing, K.B., C.F.F., A.N.G.-G. All authors have read and agreed to the published version of the manuscript.

Funding: This research received no external funding.

Conflicts of Interest: The authors declare no conflict of interest.

\section{References}

1. Zatsarinny, O.I.; Bandurina, L.A. Energy levels and lifetimes for the $2 \mathrm{p}^{5} 3 \mathrm{~s} n \ell$ core-excited states in Na. J. Phys. B At. Mol. Opt. Phys. 1993, 26, 3765-3782. [CrossRef]

2. Dorn, A.; Winnewisser, C.; Wetzstein, M.; Nienhaus, J.; Grum-Grzhimailo, A.; Zatsarinny, O.; Mehlhorn, W. Electron impact excitation and ionization of laser-excited Na atoms. J. Electron Spectrosc. Relat. Phenom. 1995, 76, 245-251. [CrossRef]

3. Dorn, A.; Zatsarinny, O.; Mehlhorn, W. Experimental and theoretical Auger and autoionization spectra for electron impact on laser-excited Na atoms. J. Phys. B At. Mol. Opt. Phys. 1997, 30, 2975-2997. [CrossRef]

4. Nienhaus, J.; Zatsarinny, O.I.; Dorn, A.; Mehlhorn, W. Electron impact excitation and ionization of laser-excited sodium atoms. J. Phys. B At. Mol. Opt. Phys. 1997, 30, 3611-3626. [CrossRef]

5. Zatsarinny, O.; Dorn, A.; Loerch, H.; Nienhaus, J.; Mehlhorn, W. Electron-impact ionization and excitation of laser-excited atoms: Investigation by means of electron spectrometry. Nucl. Inst. Meth. Phys. Res. B 1999, 154, 90-96. [CrossRef]

6. Nienhaus, J.; Zatsarinny, O.; Mehlhorn, W. Experimental and theoretical Auger and autoionization spectra for electron impact on laser-excited Ba atoms. Phys. Essays 2000, 13, 307-324. [CrossRef]

7. Feuerstein, B.; Grum-Grzhimailo, A.N.; Mehlhorn, W. Electron impact excitation cross sections of sodium autoionizing state from threshold to $1.5 \mathrm{keV}$. J. Phys. B At. Mol. Opt. Phys. 1998, 31, 593-608. [CrossRef]

8. Mazza, T.; Ilchen, M.; Kiselev, M.D.; Gryzlova, E.V.; Baumann, T.M.; Boll, R.; De Fanis, A.; Grychtol, P.; Montaño, J.; Music, V.; et al. Mapping Resonance Structures in Transient Core-Ionized Atoms. Phys. Rev. X 2020, 10, 041056. [CrossRef]

9. Kiselev, M.D.; Gryzlova, E.V.; Burkov, S.M.; Zatsarinny, O.; Grum-Grzhimailo, A.N. The mechanisms of 1s double-core hole excitation and decay in neon. Atoms 2021, 9, 114.

10. Buckman, S.J.; Hammond, P.; King, G.C.; Read, F.H. High-resolution electron impact excitation functions of metastable states of neon, argon, krypton and xenon. J. Phys. B At. Mol. Phys. 1983, 16, 4219-4236. [CrossRef]

11. Zatsarinny, O.; Bartschat, K. B-spline Breit-Pauli R-matrix calculations for electron collisions with neon atoms. J. Phys. B At. Mol. Opt. Phys. 2004, 37, 2173-2189. [CrossRef]

12. Available online: https://amosgateway.org/ (accessed on 1 December 2021).

13. Available online: https://github.com/zatsaroi/BSR3 (accessed on 1 December 2021).

14. Fernández-Menchero, L.; Zatsarinny, O.; Bartschat, K. Electron impact excitation of $\mathrm{N}^{3+}$ using the B-spline R-matrix method: Importance of the target structure description and the size of the close-coupling expansion. J. Phys. B At. Mol. Opt. Phys. 2017, 50, 065203. [CrossRef]

15. Zatsarinny, O. BSR: B-spline atomic R-matrix codes. Comput. Phys. Commun. 2006, 174, 273-356. [CrossRef]

16. Zatsarinny, O.; Bartschat, K. The B-spline R-matrix method for atomic processes: Application to atomic structure, electron collisions and photoionization. J. Phys. B At. Mol. Opt. Phys. 2013, 46, 112001. [CrossRef]

17. Bömmels, J.; Franz, K.; Hoffmann, T.H.; Gopalan, A.; Zatsarinny, O.; Bartschat, K.; Ruf, M.W.; Hotop, H. Low-lying resonances in electron-neon scattering: Measurements at $4-\mathrm{meV}$ resolution and comparison with theory. Phys. Rev. A 2005, 71, 012704. [CrossRef]

18. Allan, M.; Franz, K.; Hotop, H.; Zatsarinny, O.; Bartschat, K. Absolute angle-differential cross sections for electron-impact excitation of neon within the first $3.5 \mathrm{eV}$ above threshold. J. Phys. B At. Mol. Opt. Phys. 2009, 42, 044009. [CrossRef]

19. Bartschat, K.; Fischer, C.F.; Grum-Grzhimailo, A.N. A Tribute to Oleg Zatsarinny (1953-2021): His Life in Science. Atoms 2021, 9 , 53. [CrossRef] 
20. Dorn, A.; Nienhaus, J.; Wetzstein, M.; Winnewissert, C.; Mehlhorn, W.; Balashov, V.V.; Grum-Grzhimailo, A.N.; Kabachnik, N.M.; Zatsarinny, O.I. Angular anisotropy of autoionization electrons from sodium atoms simultaneously excited by laser and electron beams. J. Phys. B At. Mol. Opt. Phys. 1994, 27, L529-L534. [CrossRef]

21. Ren, X.; Pflüger, T.; Ullrich, J.; Zatsarinny, O.; Bartschat, K.; Madison, D.H.; Dorn, A. Low-energy electron-impact ionization of argon: Three-dimensional cross section. Phys. Rev. A 2012, 85, 032702. [CrossRef]

22. Ren, X.; Pflüger, T.; Ullrich, J.; Zatsarinny, O.; Bartschat, K.; Madison, D.H.; Dorn, A. Erratum: Low-energy electron-impact ionization of argon: Three-dimensional cross section. Phys. Rev. A 2015, 92, 019901. [CrossRef]

23. Ren, X.; Amami, S.; Zatsarinny, O.; Pflüger, T.; Weyland, M.; Dorn, A.; Madison, D.; Bartschat, K. Kinematically complete study of low-energy electron-impact ionization of argon: Internormalized cross sections in three-dimensional kinematics. Phys. Rev. A 2016, 93, 062704. [CrossRef]

24. Guan, X.; Zatsarinny, O.; Bartschat, K.; Schneider, B.I.; Feist, J.; Noble, C.J. General approach to few-cycle intense laser interactions with complex atoms. Phys. Rev. A 2007, 76, 053411. [CrossRef]

25. Guan, X.; Noble, C.J.; Zatsarinny, O.; Bartschat, K.; Schneider, B.I. Time-dependent R-matrix calculations for multiphoton ionization of argon atoms in strong laser pulses. Phys. Rev. A 2008, 78, 053402. [CrossRef]

26. Feist, J.; Zatsarinny, O.; Nagele, S.; Pazourek, R.; Burgdörfer, J.; Guan, X.; Bartschat, K.; Schneider, B.I. Time delays for attosecond streaking in photoionization of neon. Phys. Rev. A 2014, 89, 033417. [CrossRef]

27. McKenna, C.; van der Hart, H.W. Multiphoton ionization cross sections of neon and argon. J. Phys. B At. Mol. Opt. Phys. 2003, 37, 457-470. [CrossRef]

28. Dipti; Das, T.; Bartschat, K.; Bray, I.; Fursa, D.; Zatsarinny, O.; Ballance, C.; Chung, H.K.; Ralchenko, Y. Recommended electron-impact excitation and ionization cross sections for Be I. At. Data Nucl. Data Tables 2019, 127-128, 1-21. [CrossRef]

29. Wang, Y.; Zatsarinny, O.; Bartschat, K. B-spline $R$-matrix-with-pseudostates calculations for electron-impact excitation and ionization of carbon. Phys. Rev. A 2013, 87, 012704. [CrossRef]

30. Zatsarinny, O.; Wang, Y.; Bartschat, K. Relativistic B-spline R-matrix calculations for electron collisions with lead atoms: Differential cross sections and spin asymmetries. J. Phys. B At. Mol. Opt. Phys. 2013, 46, 035202. [CrossRef]

31. Wang, Y.; Zatsarinny, O.; Bartschat, K.; Booth, J.P. Fine-structure-resolved electron collisions from chlorine atoms in the $\left(3 p^{5}\right)^{2} P_{3 / 2}^{o}$ and $\left(3 p^{5}\right)^{2} P_{1 / 2}^{o}$ states. Phys. Rev. A 2013, 87, 022703. [CrossRef]

32. Wang, Y.; Zatsarinny, O.; Bartschat, K. B-spline $R$-matrix-with-pseudostates calculations for electron-impact excitation and ionization of nitrogen. Phys. Rev. A 2014, 89, 062714. [CrossRef]

33. Zatsarinny, O.; Wang, Y.; Bartschat, K. Electron-impact excitation of argon at intermediate energies. Phys. Rev. A 2014, 89, 022706. [CrossRef]

34. Wang, Y.; Wang, Y.F.; Zhu, X.M.; Zatsarinny, O.; Bartschat, K. A xenon collisional-radiative model applicable to electric propulsion devices: I. Calculations of electron-impact cross sections for xenon ions by the Dirac B-spline R-matrix method. Plasma Sources Sci. Technol. 2019, 28, 105004. [CrossRef]

35. Zhu, X.M.; Wang, Y.F.; Wang, Y.; Yu, D.R.; Zatsarinny, O.; Bartschat, K.; Tsankov, T.V.; Czarnetzki, U. A xenon collisional-radiative model applicable to electric propulsion devices: II. Kinetics of the $6 \mathrm{~s}, 6 \mathrm{p}$, and $5 \mathrm{~d}$ states of atoms and ions in Hall thrusters. Plasma Sources Sci. Technol. 2019, 28, 105005. [CrossRef]

36. Wang, K.; Zatsarinny, O.; Bartschat. Low-energy outer-shell photodetachment of the negative ion of boron. Eur. Phys. J. D 2016, 70, 72. [CrossRef]

37. Wang, K.; Zatsarinny, O.; Bartschat, K. Electron-impact excitation and ionization of atomic boron at low and intermediate energies. Phys. Rev. A 2016, 93, 052715. [CrossRef]

38. Wang, K.; Zatsarinny, O.; Bartschat, K. Low-energy photodetachment of $\mathrm{Ga}^{-}$and elastic electron scattering from neutral Ga. Phys. Rev. A 2016, 94, 023402. [CrossRef]

39. Wang, K.; Fernández-Menchero, L.; Zatsarinny, O.; Bartschat, K. Calculations for electron-impact excitation of $\mathrm{Mg}^{4+}$. Phys. Rev. A 2017, 95, 042709. [CrossRef]

40. Tayal, S.S.; Sossah, A.M. Collision rates for electron excitation of Mg V lines. AEA 2015, 574, A87. [CrossRef]

41. Aggarwal, K.M.; Keenan, F.P. Electron impact excitation rates for transitions in Mg V. Can. J. Phys. 2017, 95, 9-20. [CrossRef]

42. Wang, K.; Bartschat, K.; Zatsarinny, O. Electron Scattering from Neutral Fe and Low-energy Photodetachment of Fe ${ }^{-}$. Astrophys. J. 2018, 867, 63. [CrossRef]

43. Barklem, P.S. Accurate abundance analysis of late-type stars: Advances in atomic physics. Astron. Astrophys. Rev. 2016, 24, 63. [CrossRef]

44. Lotz, W. Electron-impact ionization cross-sections and ionization rate coefficients for atoms and ions from hydrogen to calcium. Z. Für Phys. 1968, 216, 241-247. [CrossRef]

45. Chen, Z.; Liu, F.; Wen, H.; Morishita, T.; Zatsarinny, O.; Bartschat, K. Nonsequential double ionization of Ar in near-single-cycle laser pulses. Opt. Express 2020, 28, 22231-22246. [CrossRef] [PubMed]

46. Zatsarinny, O.; Tayal, S.S. Low-energy electron collisions with atomic oxygen: R-matrix calculation with non-orthogonal orbitals. J. Phys. B At. Mol. Opt. Phys. 2001, 34, 1299-1319. [CrossRef]

47. Zatsarinny, O.; Tayal, S.S. Low-energy electron collisions with atomic sulfur: R-matrix calculation with non-orthogonal orbitals. J. Phys. B At. Mol. Opt. Phys. 2001, 34, 3383-3400. [CrossRef] 
48. Tayal, S.S.; Zatsarinny, O. Benchmark Photoionization Cross-Sections of Neutral Scandium from the Ground and Excited States. Atoms 2021, 9, 83. [CrossRef]

49. LXCat Database. Available online: https://nl.lxcat.net (accessed on 31 October 2021).

50. Grondein, P.; Lafleur, T.; Chabert, P.; Aanesland, A. Global model of an iodine gridded plasma thruster. Phys. Plasmas 2016, 23, 033514. [CrossRef]

51. Ambalampitiya, H.B.; Hamilton, K.R.; Zatsarinny, O.; Bartschat, K.; Turner, M.; Dzarasova, A.; Tennyson, J. Electron Scattering Cross-Section Calculations for Atomic and Molecular Iodine. Atoms 2021, 9, 103. [CrossRef]

52. Zatsarinny, O.; Bartschat, K.; Gedeon, S.; Gedeon, V.; Lazur, V.; Nagy, E. Cross Sections for Electron Scattering from Magnesium. Phys. Rev. A 2009, 79, 052709. [CrossRef]

53. Barklem, P.S.; Osorio, Y.; Fursa, D.V.; Bray, I.; Zatsarinny, O.; Bartschat, K.; Jerkstrand, A. Inelastic e+Mg Collision Data and Its Impact on Modelling Stellar and Supernova Spectra. Astron. Astrophys. 2017, 606, A11. [CrossRef]

54. Amarsi, A.M.; Barklem, P.S.; Asplund, M.; Collet, R.; Zatsarinny, O. Inelastic O+H Collisions and the O I 777 Nm Solar Centre-to-Limb Variation. Astron. Astrophys. 2018, 616, A89. [CrossRef]

55. Osorio, Y.; Lind, K.; Barklem, P.S.; Allende Prieto, C.; Zatsarinny, O. Ca Line Formation in Late-Type Stellar Atmospheres. I. The Model Atom. Astron. Astrophys. 2019, 623, A103. [CrossRef]

56. Reggiani, H.; Amarsi, A.M.; Lind, K.; Barklem, P.S.; Zatsarinny, O.; Bartschat, K.; Fursa, D.V.; Bray, I.; Spina, L.; Meléndez, J. Non-LTE Analysis of K I in Late-Type Stars. Astron. Astrophys. 2019, 627, A177. [CrossRef]

57. Amarsi, A.M.; Barklem, P.S.; Collet, R.; Grevesse, N.; Asplund, M. 3D Non-LTE Line Formation of Neutral Carbon in the Sun. Astron. Astrophys. 2019, 624, A111. [CrossRef]

58. Amarsi, A.M.; Grevesse, N.; Grumer, J.; Asplund, M.; Barklem, P.S.; Collet, R. The 3D Non-LTE Solar Nitrogen Abundance from Atomic Lines. Astron. Astrophys. 2020, 636, A120. [CrossRef]

59. Tayal, S.S.; Zatsarinny, O. B-spline R-matrix with Pseudostates Approach for Excitation and Ionization of Atomic Oxygen by Electron Collisions. Phys. Rev. A 2016, 94, 042707. [CrossRef]

60. Zatsarinny, O.; Parker, H.; Bartschat, K. Electron-Impact Excitation and Ionization of Atomic Calcium at Intermediate Energies. Phys. Rev. A 2019, 99, 012706. [CrossRef]

61. Asplund, M.; Amarsi, A.M.; Grevesse, N. The Chemical Make-up of the Sun: A 2020 Vision. Astron. Astrophys. 2021, 653, A141. [CrossRef]

62. Amarsi, A.M.; Nissen, P.E.; Asplund, M.; Lind, K.; Barklem, P.S. Carbon and Oxygen in Metal-Poor Halo Stars. Astron. Astrophys. 2019, 622, L4. [CrossRef]

63. Amarsi, A.M.; Nissen, P.E.; Skúladóttir, Á. Carbon, Oxygen, and Iron Abundances in Disk and Halo Stars. Implications of 3D Non-LTE Spectral Line Formation. Astron. Astrophys. 2019, 630, A104. [CrossRef] 